\title{
Normocalcemia is maintained in mice under conditions of calcium malabsorption by vitamin D-induced inhibition of bone mineralization
}

\author{
Liesbet Lieben, ${ }^{1}$ Ritsuko Masuyama, ${ }^{1}$ Sophie Torrekens, ${ }^{1}$ Riet Van Looveren, ${ }^{1}$ Jan Schrooten, ${ }^{2}$ \\ Pieter Baatsen, ${ }^{3}$ Marie-Hélène Lafage-Proust, ${ }^{4}$ Tom Dresselaers, ${ }^{5}$ Jian Q. Feng, ${ }^{6}$ \\ Lynda F. Bonewald, ${ }^{7}$ Mark B. Meyer, ${ }^{8}$ J. Wesley Pike, ${ }^{8}$ Roger Bouillon, ${ }^{1}$ and Geert Carmeliet ${ }^{1}$ \\ ${ }^{1}$ Clinical and Experimental Endocrinology, ${ }^{2}$ Department of Metallurgy and Materials Engineering, and \\ ${ }^{3}$ EM-facility of the Center of Human Genetics (VIB/KU Leuven), KU Leuven, Leuven, Belgium. ${ }^{4}$ Université de Lyon, INSERM U 1059, St-Etienne, France. \\ ${ }^{5}$ Biomedical MRI Unit/Molecular Small Animal Imaging Center, KU Leuven, Leuven, Belgium. ${ }^{6}$ Department of Biomedical Sciences, Baylor College of Dentistry, \\ Texas A\&M Health Science Center, Dallas, Texas, USA. ${ }^{7}$ Department of Oral Biology, University of Missouri at Kansas City, Kansas City, Kansas, USA. \\ ${ }^{8}$ Department of Biochemistry, University of Wisconsin-Madison, Madison, Wisconsin, USA.
}

\begin{abstract}
Serum calcium levels are tightly controlled by an integrated hormone-controlled system that involves active vitamin $\mathrm{D}\left[1,25(\mathrm{OH})_{2} \mathrm{D}\right]$, which can elicit calcium mobilization from bone when intestinal calcium absorption is decreased. The skeletal adaptations, however, are still poorly characterized. To gain insight into these issues, we analyzed the consequences of specific vitamin $\mathrm{D}$ receptor $(V d r)$ inactivation in the intestine and in mature osteoblasts on calcium and bone homeostasis. We report here that decreased intestinal calcium absorption in intestine-specific $V d r$ knockout mice resulted in severely reduced skeletal calcium levels so as to ensure normal levels of calcium in the serum. Furthermore, increased $1,25(\mathrm{OH})_{2} \mathrm{D}$ levels not only stimulated bone turnover, leading to osteopenia, but also suppressed bone matrix mineralization. This resulted in extensive hyperosteoidosis, also surrounding the osteocytes, and hypomineralization of the entire bone cortex, which may have contributed to the increase in bone fractures. Mechanistically, osteoblastic VDR signaling suppressed calcium incorporation in bone by directly stimulating the transcription of genes encoding mineralization inhibitors. Ablation of skeletal $V d r$ signaling precluded this calcium transfer from bone to serum, leading to better preservation of bone mass and mineralization. These findings indicate that in mice, maintaining normocalcemia has priority over skeletal integrity, and that to minimize skeletal calcium storage, $1,25(\mathrm{OH})_{2} \mathrm{D}$ not only increases calcium release from bone, but also inhibits calcium incorporation in bone.
\end{abstract}

\section{Introduction}

Ionized serum calcium levels are critical for the correct functioning of multiple vital cellular processes. Accordingly, the regulation of calcium homeostasis is directed at maintaining serum calcium levels within a narrow physiological range. Briefly, hypocalcemia leads to increased parathyroid hormone (PTH) secretion, which stimulates renal calcium reabsorption and bone resorption. PTH also enhances production of the active form of vitamin D, $1,25(\mathrm{OH})_{2}$ vitamin $\mathrm{D}\left[1,25(\mathrm{OH})_{2} \mathrm{D}\right]$, which activates the vitamin $\mathrm{D}$ receptor (VDR) in the intestine to increase calcium absorption, and in bone to induce bone resorption (1).

Because the diet is the only source of calcium to the body, dietary calcium content is critical for calcium homeostasis. At low dietary calcium intake, active calcium transport controlled by $1,25(\mathrm{OH})_{2} \mathrm{D}$ predominates, whereas at high calcium intake, calcium is absorbed via passive diffusion. This model is supported by the observation that intestinal calcium transport is reduced in systemic $V d r$-null mice, leading to hypocalcemia, hypophosphatemia, and bone abnormalities that include rickets and hyperosteoidosis. The finding that a high calcium/lactose diet prevents this phenotype con-

Conflict of interest: The authors have declared that no conflict of interest exists. Citation for this article: JClin Invest. 2012;122(5):1803-1815. doi:10.1172/JCI45890. firms that VDR signaling in bone is not essential when sufficient dietary calcium is absorbed $(2,3)$.

A major disadvantage of the systemic $V d r$-null mouse model is that the expected $1,25(\mathrm{OH})_{2} \mathrm{D}$-mediated skeletal and renal adaptations to reduced intestinal calcium absorption do not occur, due to the lack of VDR activity in these tissues. Consequently, systemic $V d r$-null mice are not the appropriate model to unravel the physiological repercussions of negative calcium balance - or lack of intestinal $1,25(\mathrm{OH})_{2} \mathrm{D}$ activity - on serum calcium levels and bone homeostasis. The finding that the bone mass of $V d r$-null mice receiving a normal diet is surprisingly well preserved and characterized by increased bone formation and normal bone resorption (3) instead points toward a defect in the transfer of calcium stored in bone to serum when skeletal VDR activity is lacking. The action of $1,25(\mathrm{OH})_{2} \mathrm{D}$ therefore seems to be important in the normal skeletal responses that prevent hypocalcemia during a negative calcium balance. Previous dietary studies have shown that the amount of calcium stored in bone declines when dietary calcium supply is insufficient (4). However, the molecular skeletal adaptations that redirect calcium from bone to serum are still not identified. The question also remains whether the preservation of normal serum calcium levels is aimed for at all times, even when this adaptation damages skeletal integrity and eventually leads to bone fractures. 

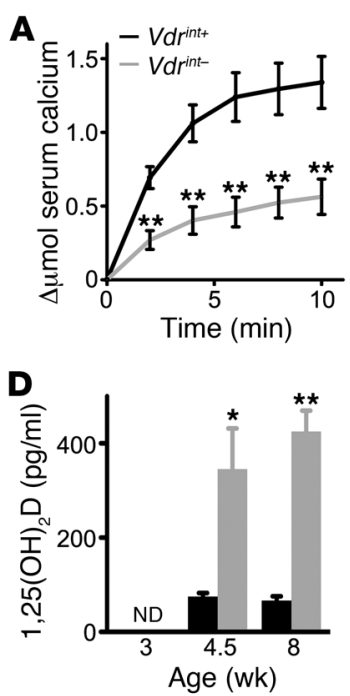

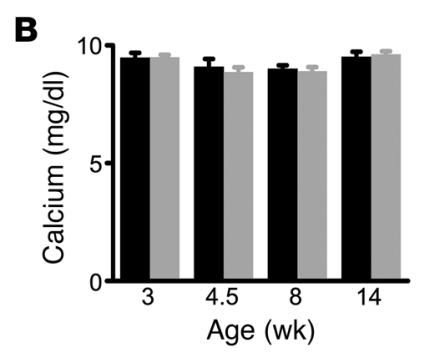

E

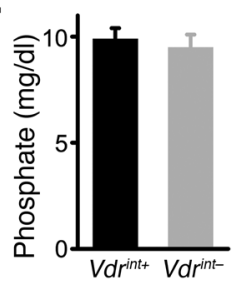

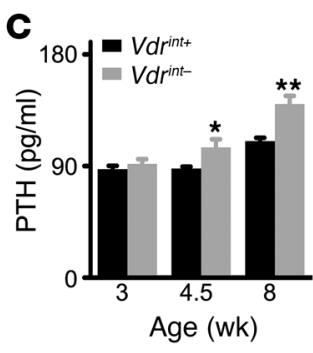

Figure 1

Effect of decreased intestinal calcium absorption on calcium homeostasis. (A) Intestinal calcium absorption, assessed by serum levels of ${ }^{45} \mathrm{Ca}(\Delta \mu \mathrm{mol})$ after oral gavage. $n=5$. (B-D) Serum levels of total calcium (B), PTH (C), and $1,25(\mathrm{OH})_{2} \mathrm{D}(\mathrm{D})$. ND, not determined. $n=5-8$. (E) Serum phosphate levels. $n=9$. ${ }^{*} P<0.05$, ${ }^{* *} P<0.01$.
Insight into these remaining issues is important for correct administration of calcium and vitamin D supplements. Elderly individuals are especially at risk for a negative calcium balance, because their diet is frequently calcium insufficient. Calcium supplements are therefore commonly used to reduce bone loss. Vitamin D is often added as a supplement, despite the ongoing debate on the efficacy and safety of several vitamin $\mathrm{D}$ therapeutic regimens. Indeed, a recent study reports that annual oral administration of high-dose vitamin $\mathrm{D}$ to older women results in an increased risk of fractures $(5,6)$. Because an explanation for this unexpected outcome is currently lacking, thorough insight into the mechanisms by which vitamin $\mathrm{D}$ regulates calcium homeostasis is warranted. An argument in favor of vitamin D supplementation is that correcting vitamin D deficien$c y$, which is frequently observed in the elderly, may improve intestinal calcium absorption and thus indirectly increase bone mass. On the other hand, increased $1,25(\mathrm{OH})_{2} \mathrm{D}$ levels may be deleterious to the skeleton, as they stimulate osteoclast formation (7), and several case reports mention the observation of increased unmineralized bone matrix after occult vitamin $\mathrm{D}$ intoxication, but do not provide a molecular mechanism (8). Understanding the hierarchy of serum and skeletal calcium and the role of $1,25(\mathrm{OH})_{2} \mathrm{D}$ therein is needed to improve the current therapeutic strategies for osteoporosis.

To elucidate the consequences of insufficient $\left[1,25(\mathrm{OH})_{2} \mathrm{D}\right.$ mediated] intestinal calcium absorption on serum calcium levels, and how this negative calcium balance affects bone homeostasis, we compared calcium homeostasis in intestinal-specific $V d r$-null mice with that in systemic and osteocyte-specific $V d r$-null mice. Our study provided evidence that stimulation of intestinal calcium transport by $1,25(\mathrm{OH})_{2} \mathrm{D}$ is already important during normal calcium intake, and that when this process is hampered, a physiological increase in $1,25(\mathrm{OH})_{2} \mathrm{D}$ levels affects bone negatively. These findings support the concept that maintaining normocalcemia has hierarchical priority over the preservation/accretion of bone mass, even when these adaptations result in osteopenia and fractures, and that $1,25(\mathrm{OH})_{2} \mathrm{D}$ regulates the shift of skeletal calcium toward serum by controlling the level of mineralization inhibitors.

\section{Results}

Intestinal Vdr deletion reduces calcium absorption, but not serum calcium levels. To genetically assess the importance of $1,25(\mathrm{OH})_{2} \mathrm{D}$ - mediated intestinal calcium absorption, $V d r$ was efficiently and specifically inactivated in the intestines of mice (referred to herein as $V d r^{\text {int- }}$ mice; see Methods and Supplemental Figure 1, A and B; supplemental material available online with this article; doi:10.1172/JCI45890DS1). $V d r^{\text {int }}$ mice were born at the expected Mendelian ratio (data not shown) and showed normal body weight gain (Supplemental Figure 1C). As expected, loss of intestinal $V d r$ decreased active intestinal ${ }^{45} \mathrm{Ca}^{2+}$ absorption (Figure $1 \mathrm{~A}$ ) and reduced transcript levels of the intestinal calcium transport proteins (Supplemental Figure 1D).

Despite the decreased intestinal calcium absorption, total and ionized serum calcium levels were normal in $V d r^{\text {int- }}$ mice (ionized serum $\mathrm{Ca}^{2+}, 5.33 \pm 0.03 \mathrm{mg} / \mathrm{dl}$ in $V d r^{\text {int+ }}$ control vs. $5.27 \pm 0.06$ $\mathrm{mg} / \mathrm{dl}$ in $V d r^{\text {int }-} ; n=8$; Figure $\left.1 \mathrm{~B}\right)$. This finding contrasts with the hypocalcemia observed in $V d r$-null mice, although intestinal calcium absorption is similarly reduced (9). These data indicate that $V d r^{\text {int- }}$ mice, but not $V d r^{-1-}$ mice, can balance the reduced calcium absorption by compensatory mechanisms in order to preserve normocalcemia. Serum levels of the calciotropic hormones PTH and $1,25(\mathrm{OH})_{2} \mathrm{D}$ were indeed increased in $V d r^{\text {int- }}$ mice from weaning onward, the time period at which active intestinal calcium absorption becomes crucial (Figure 1, C and D, and Supplemental Figure 1, E and F). Of note, serum phosphate levels were comparable between genotypes (Figure 1E). These findings indicated that intestinal $V d r$ expression is crucial for optimal calcium absorption and that the preservation of normocalcemia is the primary objective whenever increased $1,25(\mathrm{OH})_{2} \mathrm{D}$ levels can turn on compensatory mechanisms.

Impaired calcium absorption reduces bone mass accrual, but not bone growth. Most of the body's calcium is stored in bone, where it provides strength to the skeleton, but skeletal calcium can also be transferred to serum when the calcium balance is negative. We therefore analyzed bone homeostasis in $V d r^{\text {int- }}$ and $V d r^{-1-}$ mice. The length and cross-sectional area of the tibiae of $V d r^{\text {int }}$ - mice were indistinguishable from those of control littermates (Figure 2, A and B), which indicates that longitudinal and radial bone growth was not hampered. $V d r^{-/-}$mice, on the other hand, were growth retarded and showed decreased bone length at 8 weeks of age (Supplemental Figure 2A). The rachitic growth plate phenotype, typically associated with lack of vitamin D signaling, was only 
A

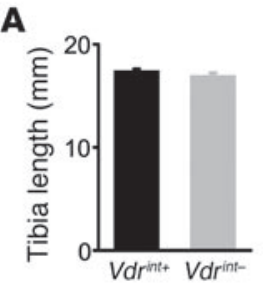

B

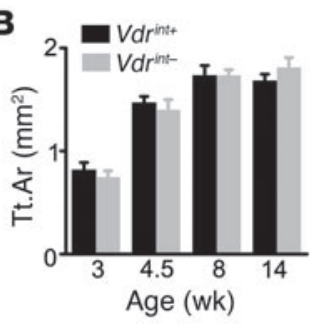

C

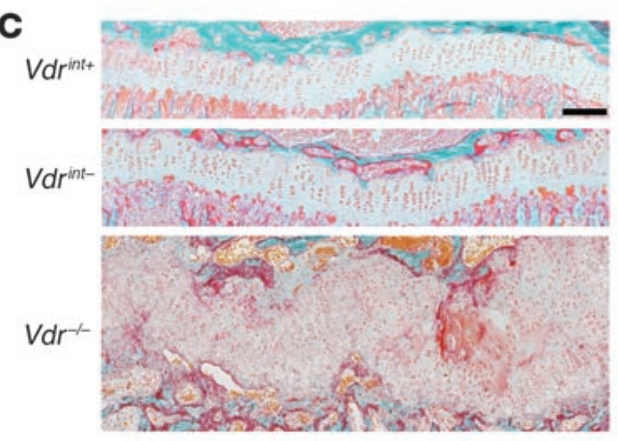

D
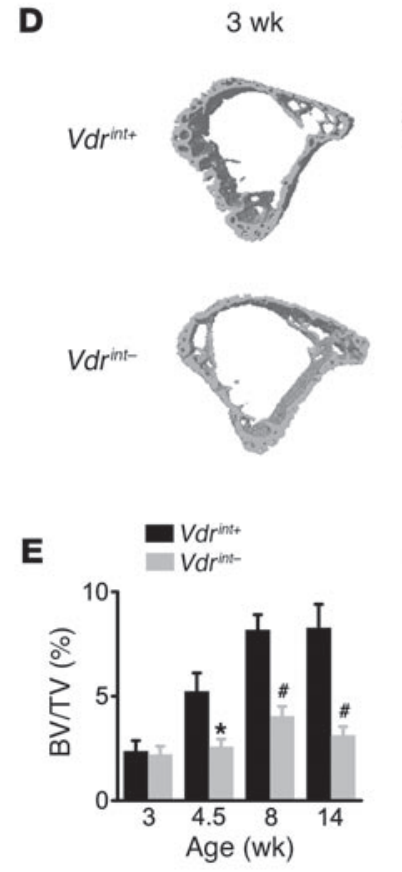

$4.5 \mathrm{wk}$
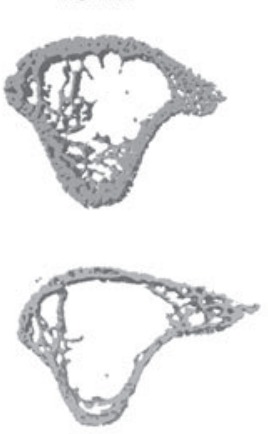

$\mathbf{F}$

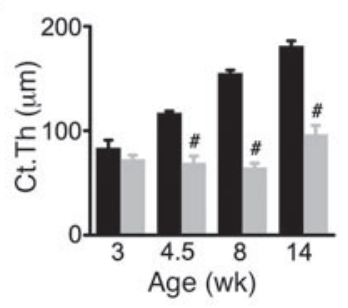

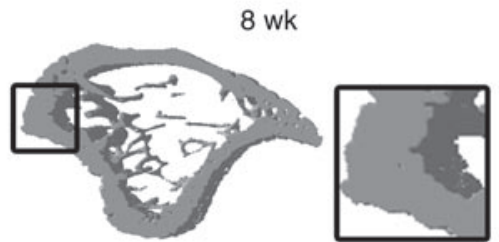

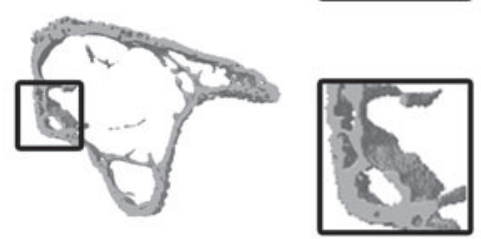

G

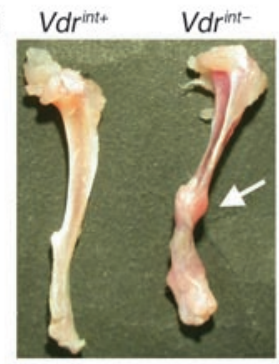

Figure 2

Normal skeletal growth, but reduced bone mass accrual, in Vdrint- mice. (A) Length of the tibia. $n=10$. (B) Quantification of the cross-sectional area of the tibia (Tt.Ar) by $\mu$ CT. $n=6-9$. (C) Representative Goldner staining of the growth plate. Scale bar: $200 \mu \mathrm{m}$. (D-F) Cross-sectional 3D $\mu C T$ images of the tibia (D) and quantification of BV/TV (E) and Ct.Th $(\mathbf{F}) . n=9$. The boxed region in $\mathbf{D}$ is a magnified view (enlarged $\times 2.4-$ fold) showing cortical porosity in 8-week-old Vdrint- mice. (G) Representative image of spontaneous bone fractures in Vdrint- mice and subsequent callus formation (arrow). ${ }^{*} P<0.05,{ }^{\#} P<0.001$ vs. Vdrint+

observed in $V d r^{--}$mice, not in $V d r^{\text {int }}$ - mice (Figure 2C and Supplemental Figure 2B). These data confirmed that normal serum calcium and phosphate levels are sufficient for normally structured growth plate and bone growth (7).

In contrast to normal bone growth, postweaning bone mass accrual was manifestly reduced in $V d r^{\text {int }}$ - mice, leading to a decrease in trabecular bone volume (BV/TV) and cortical thickness (Ct.Th) as well as an increase in cortical porosity (Figure 2, D-F, and Supplemental Figure 2, C-F). Not only the long bones were affected, but also the calvariae and vertebrae (Supplemental Figure 2, G and $\mathrm{H})$. This low bone mass caused the long bones to be very fragile: spontaneous bone fractures and healing calluses were frequently observed in $V d r^{\text {int }}$ - mice, but never in control mice ( $10 \%$ vs. $0 \%$ incidence; $n=30$; Figure 2G).

On the other hand, spontaneous bone fractures have not been reported in $\mathrm{Vdr}^{-/}$mice fed a normal calcium diet, which suggests that bone mass and/or quality is better preserved in $\mathrm{Vdr}^{-/}$than $V d r^{\text {int }}$ mice. Indeed, mineralized BV/TV was decreased in the metaphysis of the tibiae of $\mathrm{Vdr} /$ mice, but not in the proximity of the growth plate, where it was even increased (2). In addition, the Ct.Th in the diaphysis was reduced by $33 \%$ in $V d r /$ compared with $V d r^{+/+}$mice $(n=6 ; P<0.001)$, a reduction not as dramatic as the $60 \%$ decrease in $V d r^{\text {int- }}$ versus $V d r^{\text {int }}$ mice $(n=9 ; P<0.001)$. Thus, when only VDR-dependent calcium absorption is decreased, bone growth is secured, but the acquisition of mineralized bone mass is reduced, likely to avoid hypocalcemia.

Increased bone turnover contributes to normocalcemia. Bone mass accrual results from bone formation outpacing bone resorption, and an imbalance between these processes may explain the reduced bone mass in $V d r^{\text {int }}$ - mice (7). As analyzed by serum CTx levels, bone resorption was increased in $V d r^{\text {int }}$ mice (Figure 3A). Accordingly, staining for tartrate-resistant acid phosphatase (TRAP) showed 
A

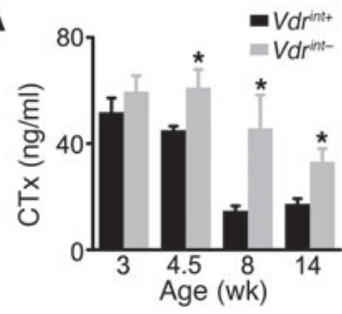

E

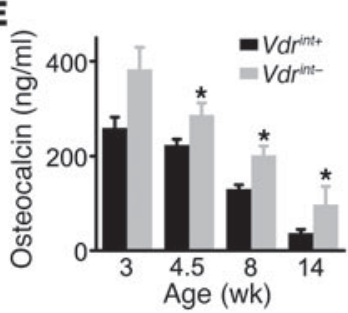

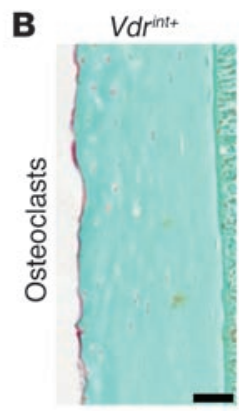
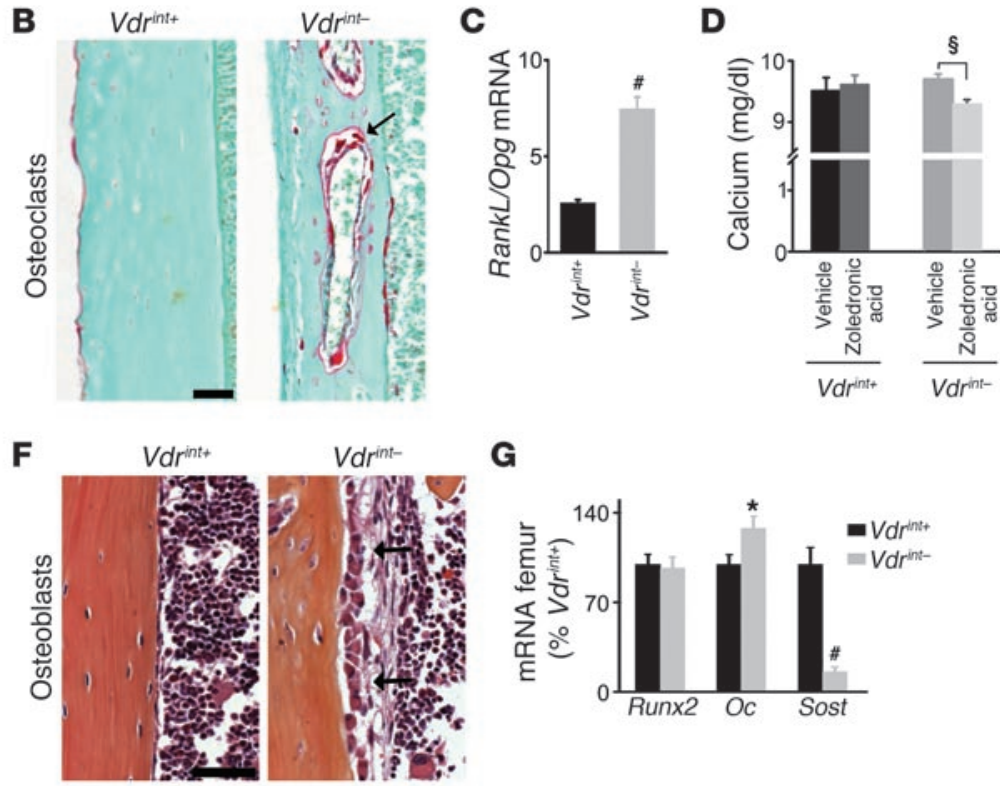

G

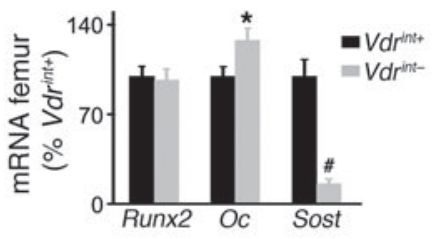

\section{Figure 3}

Increased bone remodeling in Vdrint- mice. (A) Serum CTx levels. $n=5-8$. (B) Sections of the tibia cortex stained for TRAP reactivity, showing osteoclasts in red (arrow). Scale bar: $100 \mu \mathrm{m}$. (C) Ratio of RankL mRNA to Opg mRNA in the femur. $n=8$. (D) Serum calcium levels in 14-weekold mice after treatment with vehicle or zoledronic acid for 6 weeks. $n=4-8$. (E) Serum osteocalcin levels. $n=7$. (F) H\&E staining demonstrated increased abundance of cuboidal active osteoblasts lining the cortex (arrows) in Vdrint- mice. Scale bar: $50 \mu \mathrm{m}$. (G) Gene expression by qRT-PCR in the femur. $n=8$. ${ }^{\star} P<0.05,{ }^{\#} P<0.001$ vs. Vdrint+; $\$ P<0.05$ as indicated by the bracket.

that osteoclasts were prominently present in the tibial cortex of $V d r^{\text {int }}$ mice, where they formed large resorption cavities, a feature not observed in $V d r^{i n t+}$ mice (Figure 3B). The osteoclast surface in the trabecular region was comparable between genotypes (Supplemental Figure 3A). The increased abundance of osteoclasts correlated with the upregulated mRNA ratio of Rankl (also known as Tnfsf11) to osteoprotegerin (Opg; also known as Tnfrsf11b) in the femora of $V d r^{\text {int }}$ - mice (Figure 3C and Supplemental Figure 3, $\mathrm{B}$ and $\mathrm{C})$. The number of osteoclast precursors, assessed by flow cytometry, and the in vitro differentiating capacity of hematopoietic precursors to mature osteoclasts was comparable between genotypes (Supplemental Figure 3, D and E). These data indicate that the high number of osteoclasts in $V d r^{\text {int- }}$ mice results from increased levels of osteoclastogenic factors.

To verify that the increased bone resorption was a critical mechanism to preserve normocalcemia, we treated mice from 8 to 14 weeks of age with the antiresorptive agent zoledronic acid. As expected, this treatment successfully inhibited bone resorption and increased bone volume in $V d r^{\text {int }}$ mice, without influencing serum calcium levels. Although bone resorption was not fully normalized in zoledronic acid-treated $V d r^{\text {int- }}$ mice, BV/TV was clearly increased and serum calcium levels were significantly decreased compared with vehicle-treated $V d r^{\text {int- }}$ mice (Figure 3D and Supplemental Figure 3, F and G). These observations indicated that bone resorption contributes to maintaining normocalcemia when intestinal calcium absorption is decreased.

Bone formation was also increased in $V d r^{\text {int- }}$ mice. Serum osteocalcin, a marker for bone formation, was elevated from weaning on (Figure 3E). This finding was in accord with the high number of cuboidal osteoblasts lining the cortex and trabeculae of $V d r^{i n t-}$ mice (Figure $3 \mathrm{~F}$ and Supplemental Figure $3 \mathrm{H}$ ) and with the increased osteocalcin (Oc; also known as Bglap) mRNA levels in the femora (Figure $3 \mathrm{G}$ ). The early osteoblastic differentiation stages were apparently not affected, as gene expression of the early differentiation marker runt related transcription factor 2 (Runx2) was comparable between genotypes (Figure $3 \mathrm{G}$ ). The osteogenic differentiation of bone marrow stromal cells in vitro was also not altered in $V d r^{\text {int }}$ mice (Supplemental Figure 3I), which suggests that the increase in mature osteoblasts in vivo is caused by local or systemic factors. Taken together, these observations indicate that the impaired bone mass acquisition in $V d r^{\text {int- }}$ mice results from increased bone turnover that permits skeletal growth but reduces calcium storage in bone.

Impaired mineralization contributes to the reduced skeletal calcium content in $V d r^{\text {int- }}$ mice. The increased bone turnover and resulting low bone mass in $V d r^{\text {int }}$ - mice promoted transfer of calcium from bone to serum. We next tested the hypothesis that a reduction in the degree of mineralization of the bone matrix additionally limits calcium storage in bone. The total calcium content of dry bone was reduced in $V d r^{\text {int- }}$ mice (Figure $4 \mathrm{~A}$ ). Goldner staining revealed a manifest increase in the abundance of unmineralized matrix (osteoid) on the trabeculae of $V d r^{\text {int }}$ mice (Figure 4B). Notably, this increase in osteoid did not compensate for the decreased mineralized bone mass (Figure 2E), and consequently, total bone mass was clearly reduced in $V d r^{\text {int }}$ compared with $V d r^{\text {int }}$ mice (Supplemental Figure 4A). Moreover, the endocortical surface and the cortical resorption cavities were covered with very thick osteoid seams (Figure 4C). Cortical $V d r^{\text {int- }}$ osteocytes were surrounded by a hypomineralized area, whereas osteocytes in $V d r^{\text {int }}$ mice were closely encircled by mineralized bone (Figure 4C). Energy dispersive X-ray point analyses confirmed that in $V d r^{\text {int- }}$ mice, the perilacunar area contained less calcium and phosphate than did the surrounding 
A

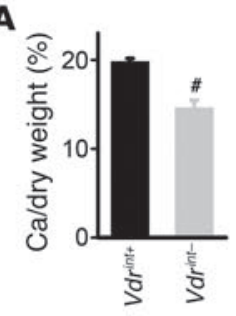

B

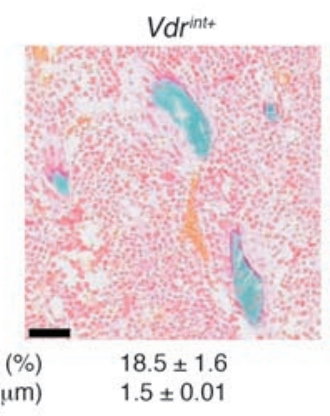

C

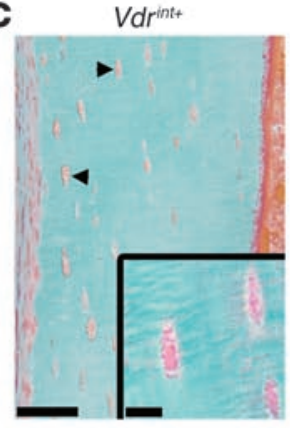

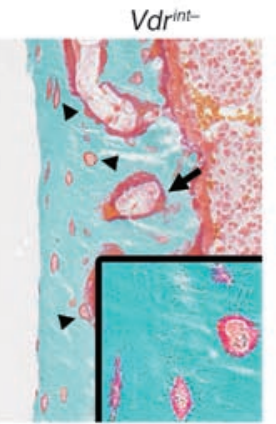
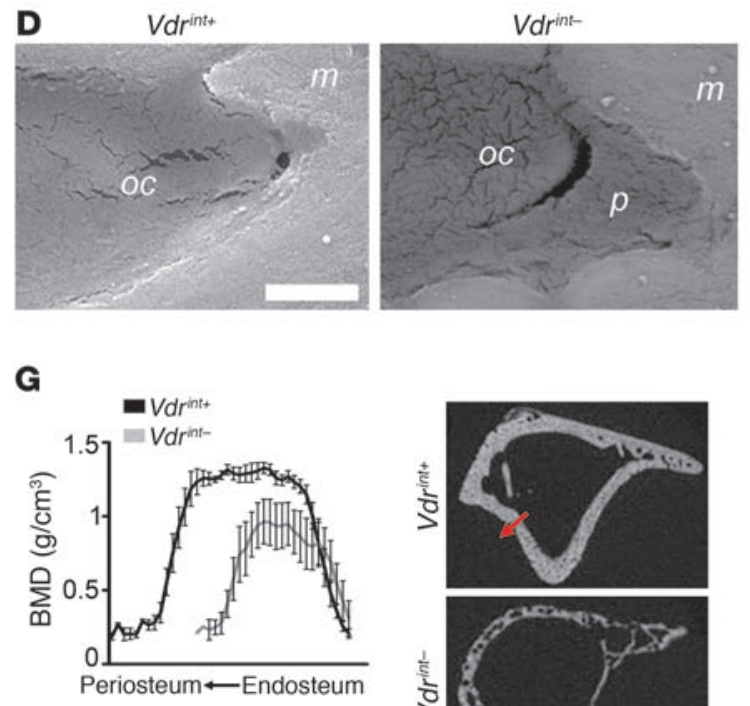

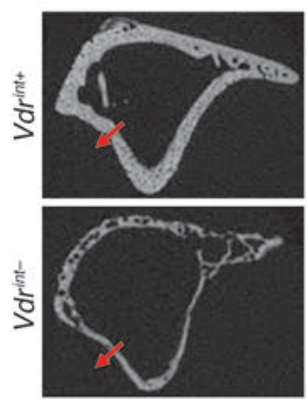

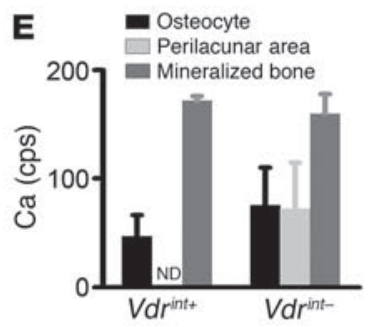

H
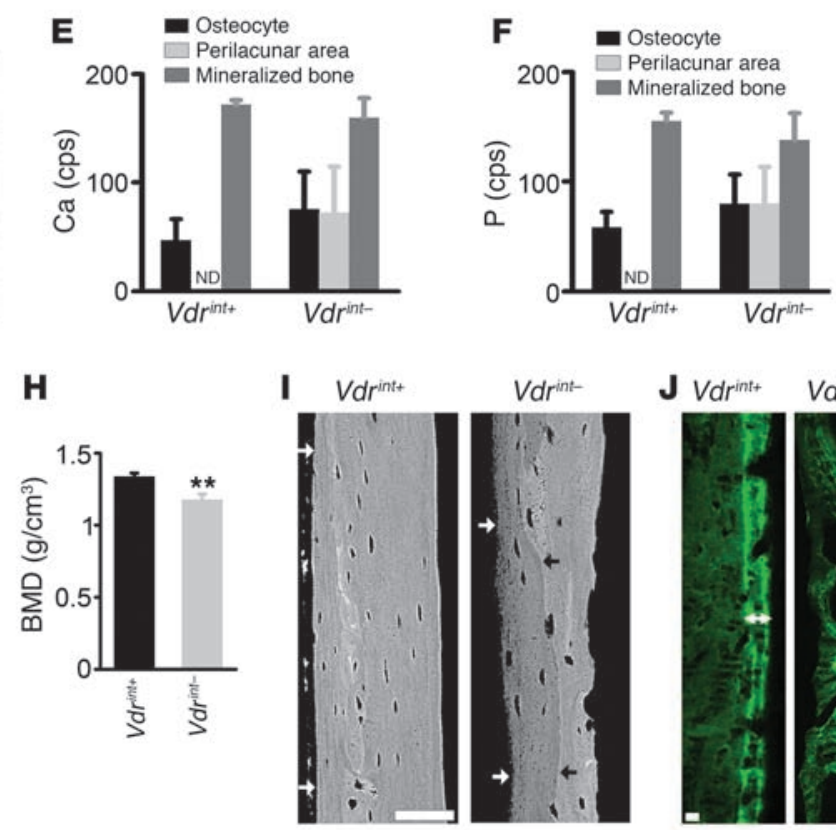

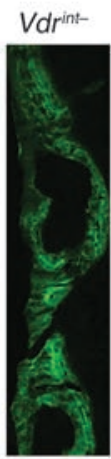

\section{Figure 4}

Decreased bone mineralization in Vdrint- mice. (A) Calcium amount, expressed as a percentage of tibial dry weight (both in milligrams). $n=10$. (B and C) Goldner staining showing osteoid on the trabeculae (arrow; B), cortical surfaces (C), and resorption cavities (arrow; C) and surrounding the osteocytes (arrowhead; C, inset) in Vdrint- mice. Quantification of osteoid surface (OS/BS) and thickness (O. Th) is also shown in B. $n=8$. Scale bars: $50 \mu \mathrm{m}$; $10 \mu \mathrm{m}$ (insets). (D) BSE of a cortical osteocyte (oc), which was directly enclosed by the mineralized matrix (m) in Vdrint+ mice, but surrounded by a hypomineralized area $(p)$ in Vdrint- mice. $n=3$. Scale bar: $2 \mu \mathrm{m}$. (E and F) Semiquantification (counts per second [cps]) of Ca (E) and $\mathrm{P}(\mathbf{F})$ by energy dispersive X-ray point analysis in the regions indicated in $\mathbf{D} . n=3$. (G and $\mathbf{H})$ Quantification of cortical BMD by $\mu \mathrm{CT}$ along a line from the endosteal to the periosteal side (G; note decreased Ct.Th in Vdrint- mice) and in a predefined region (H). $n=8$. (I) BSE image of the diaphyseal cortex showing hypomineralization of the periosteal bone in Vdrint- mice, reflected by the darker gray starting from the black arrow up to the outer cortex (white arrow), but not in control mice. Scale bar: $50 \mu \mathrm{m}$. (J) Analysis of dynamic bone formation parameters by sequential injection with calcein showing normal double label formation (double-sided arrow) in Vdrint+ mice. Scale bar: $25 \mu \mathrm{m}$. ${ }^{\star \star} P<0.01,{ }^{\#} P<0.001$ vs. Vdrint+ .

fully mineralized bone (Figure 4, D-F). Thus, Vdrint- osteocytes are flanked by a transitional area that contains reduced amounts of calcium and phosphate.

In addition to the local hyperosteoidosis, the cortical bone was overall hypomineralized in $V d r^{i n t-}$ mice. Micro-CT $(\mu \mathrm{CT})$ analysis showed that the bone mineral density (BMD) was profoundly decreased, either measured across the cortex or in a defined region of interest (Figure 4, G and H, and Supplemental Figure 4B). These data were confirmed by backscattered electron microscopy (BSE), in which lighter gray levels reflect increased amounts of incorporated mineral. The gray level was darker at the periosteal site than at the endosteal site in $V d r^{\text {int }}$ - mice, indicative of decreased mineral content at the site where new bone is formed. This fea- ture was evident at 4.5 weeks of age (Supplemental Figure 4C), very prominent at 8 weeks of age (Figure 4I), and not observed in the other groups. Anomalous dynamic bone formation parameters, analyzed via sequential injection of calcein, confirmed the mineralization defects (Figure 4J and Supplemental Figure 4D). $V d r^{\text {int }}$ mice showed a normal mineralization pattern, reflected by discernible double labels, whereas fluorochrome incorporation in the cortex and trabeculae of $V d r^{\text {int- }}$ mice was aberrant and scattered without clear double labeling. Thus, $V d r^{\text {int }}$ - mice suffered from severe mineralization defects characterized by extensive hyperosteoidosis, even surrounding the osteocytes, and by global hypomineralization of the mineralized bone matrix, whereas serum calcium and phosphate levels were normal. This finding 


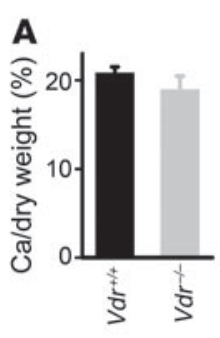

B
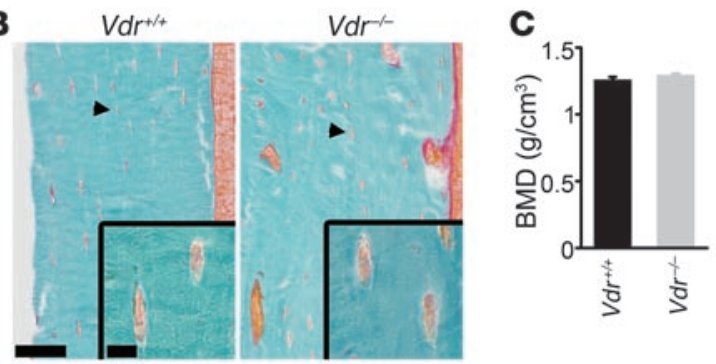

\section{Figure 5}

Normal bone mineralization in $V d r^{-1-}$ mice. (A) Calcium amount, expressed as a percentage of tibial dry weight (both in milligrams). $n=10$. (B) Goldner-stained sections of the tibial cortex, with osteocytes (arrowhead) shown magnified (insets). Scale bars: $50 \mu \mathrm{m}$; $10 \mu \mathrm{m}$ (insets). (C and D) Quantification of cortical BMD by $\mu \mathrm{CT}$ in a predefined region (C) and along a line from the endosteal to the periosteal side (D). $n=8$. (E) BSE image of the diaphyseal cortex. White arrows denote the periosteal side. Scale bar: $50 \mu \mathrm{m}$.
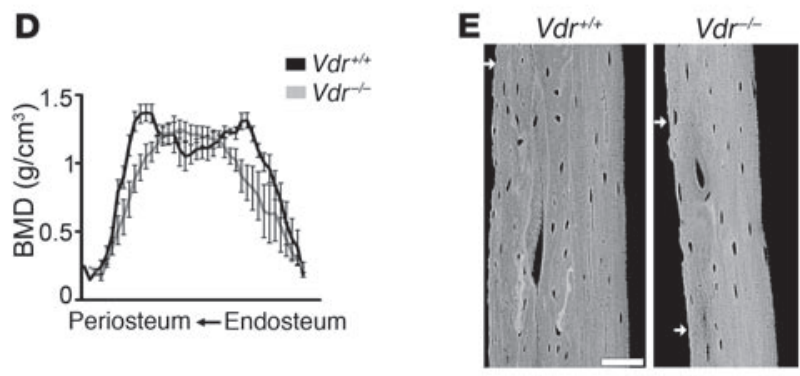

implies that calcium storage in bone is reduced to maintain normocalcemia, not only by increased bone resorption, but also by inhibited mineral deposition.

Increased skeletal VDR signaling suppresses skeletal calcium incorporation. To explain the mineralization defects in $V d r^{\text {int- }}$ mice in light of the normocalcemia, we postulated that the high $1,25(\mathrm{OH})_{2} \mathrm{D}$ levels inhibit bone matrix mineralization. Arguments for this hypothesis are provided by the disparity of the skeletal findings between the $V d r^{\text {int- }}$ and $V d r^{-1}$ phenotypes. The osteoid excess in $V d r^{-1}$ mice is considered to result from severe hypocalcemia and hypophosphatemia, whereas the hyperosteoidosis in $V d r^{i n t-}$ mice is associated with normal serum calcium and phosphate levels. These findings suggest that hormonal changes lead to the mineralization defects in $V d r^{\text {int }}$ mice. Serum PTH and $1,25(\mathrm{OH})_{2} \mathrm{D}$ levels are increased in $V d r^{-/-}$mice as well as $V d r^{\text {int- }}$ mice, but skeletal VDR signaling is only possible in $V d r^{\text {int- }}$ mice, whereas PTH can act in both genotypes. In addition, the mineralization defects were less pronounced in the $V d r^{-1}$ mice, as evidenced by the normal low calcium content in dry bone, the lack of hyperosteoidosis at the osteocyte lacunae, and the normal cortical BMD (Figure 5 and Supplemental Figure $4 \mathrm{E})$. These data suggest that skeletal VDR signaling may contrib- ute to hypomineralization. In addition, $1,25(\mathrm{OH})_{2} \mathrm{D}_{3}$ treatment of 7-week-old wild-type mice caused profound mineralization defects, an effect that was completely prevented when VDR signaling was inactivated in the mature osteoblastic lineage (see below). Moreover, $1,25(\mathrm{OH})_{2} \mathrm{D}_{3}$ treatment of in vitro-differentiated osteoblastic cells decreased matrix mineralization (Figure 6 and Supplemental Figure 5, A and B). Together, these observations suggest that high $1,25(\mathrm{OH})_{2} \mathrm{D}$ levels suppress bone matrix mineralization.

Increased circulating $1,25(\mathrm{OH})_{2} \mathrm{D}$ levels impair mineralization by upregulating expression of mineralization inhibitors. Mineralization of the organic bone matrix is promoted by calcium and phosphate and the presence of matrix proteins like collagen I (COL1a1), but counteracted by mineralization inhibitors, including pyrophosphates (PPis) and small integrin binding ligand N-linked glycoprotein (SIBLING) proteins such as osteopontin (OPN; also known as SPP1) (10). Serum calcium and phosphate levels were normal in Vdrint- mice, and Col1a1 was abundantly expressed in bone (Supplemental Figure 5C), which indicates that these factors could not account for the mineralization defects. We therefore postulate that $1,25(\mathrm{OH})_{2} \mathrm{D}$ suppresses mineralization by regulating the levels of mineralization inhibitors.

\section{Figure 6}

$1,25(\mathrm{OH})_{2} \mathrm{D}$ suppresses mineralization in vitro by increasing PPi levels. Quantification of PPi levels in conditioned medium corrected for DNA content, and visualization of the mineralization by Alizarin red staining, in differentiated $\mathrm{Vdr}+/+$ osteoblasts after treatment for 4 days with vehicle (veh), $10^{-8} \mathrm{M}$ $1,25(\mathrm{OH})_{2} \mathrm{D}_{3}(1,25 \mathrm{D}), 1 \mathrm{U} / \mathrm{ml}$ TNAP, and $5 \times 10^{-6} \mathrm{M} P P i$ as indicated. $n=6$. ${ }^{*} P<0.05$ as indicated by brackets, 1-way ANOVA followed by Fisher's LSD multiple-comparison test.

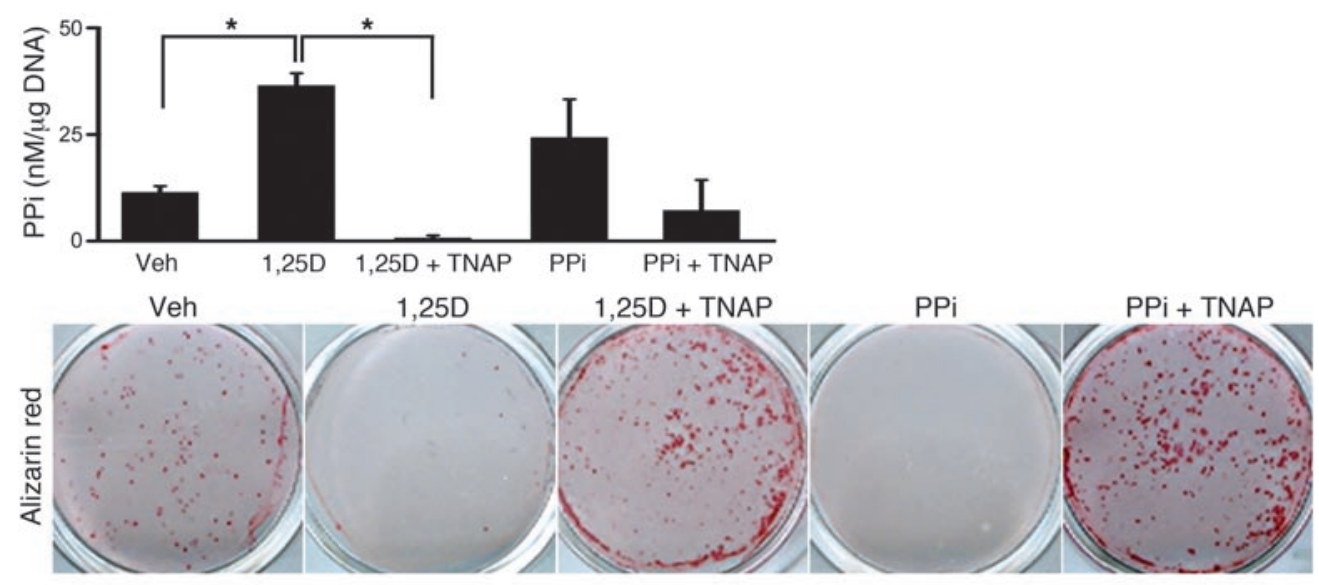



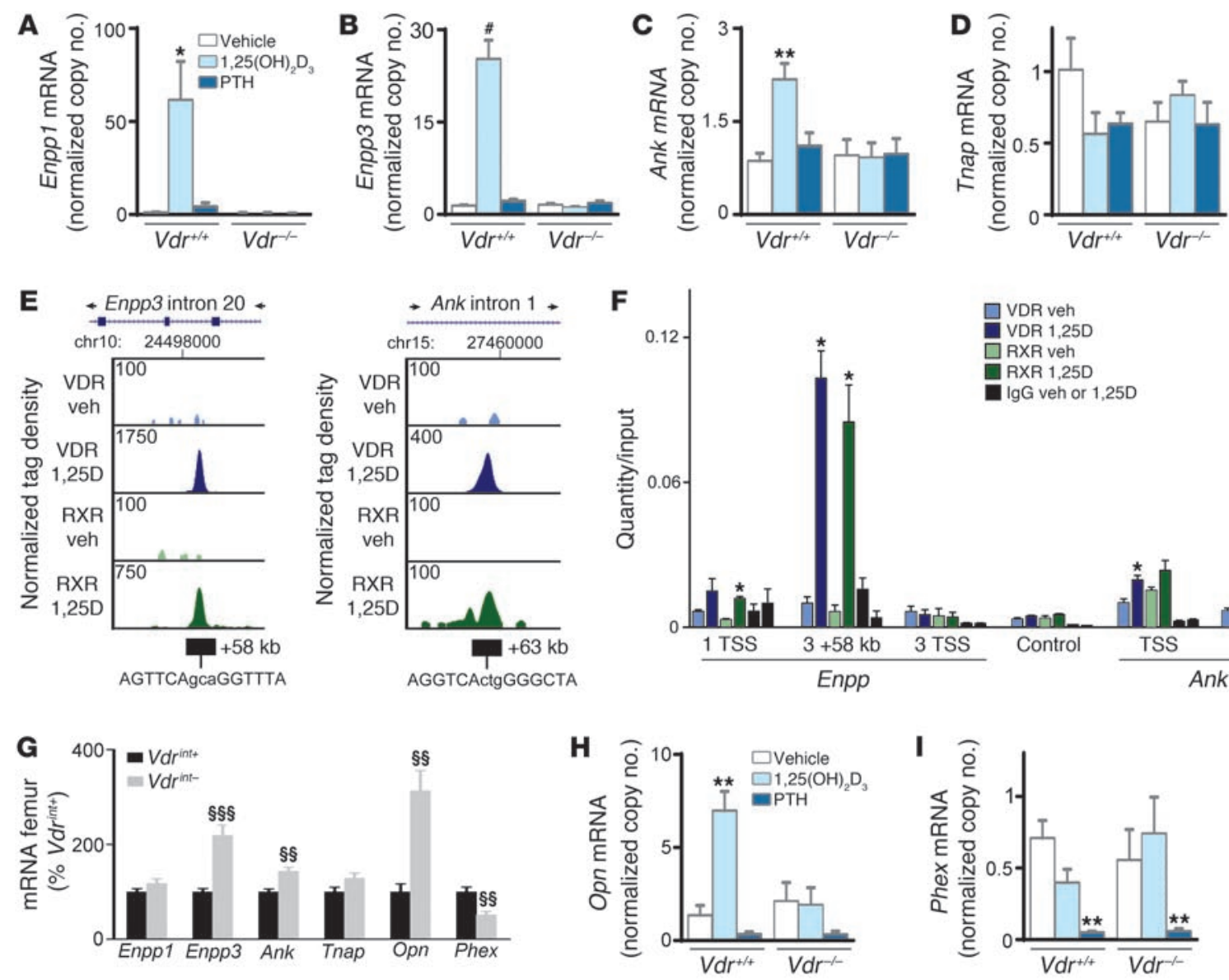

Figure 7

Molecular mechanism of $1,25(\mathrm{OH})_{2} \mathrm{D}$-induced suppression of mineralization. (A-D, $\mathbf{H}$, and $\left.\mathbf{I}\right)$ Gene expression analysis by qRT-PCR in in vitro-differentiated osteoblasts after treatment with vehicle, $10^{-8} \mathrm{M} \mathrm{1,25}(\mathrm{OH})_{2} \mathrm{D}_{3}$, and $2.5 \times 10^{-8} \mathrm{M}$ PTH for 24 hours. Values denote mRNA copy number normalized to that of Hprt (see Methods). $n=6$. (E) ChIP-seq tag density profiles for VDR (blue) and RXR (green) after treatment with vehicle or $10^{-7} \mathrm{M} 1,25(\mathrm{OH})_{2} \mathrm{D}_{3}(1,25 \mathrm{D})$ for 3 hours in MC3T3-E1 cells. Data centered around the Enpp3 and Ank peak genomic locus are shown, with arrows indicating the direction of gene transcription. ChIP-seq tag densities were normalized to $1 \times 10^{7}$ tags; tag maximum for the data is shown at top left of each track. (F) qRT-PCR quantification of ChIP-DNA, obtained from MC3T3-E1 cells treated with vehicle or $1,25(\mathrm{OH})_{2} \mathrm{D}_{3}$ $\left(10^{-7} \mathrm{M}\right.$ for 3 hours) prior to ChIP with VDR, RXR, and nonspecific IgG antibodies, with primers flanking the TSS of Enpp1 (1 TSS), the +58-kb peak in and the TSS of Enpp3 $(3+58 \mathrm{~kb}$ and 3 TSS, respectively), the TSS of and the $+63-\mathrm{kb}$ peak in Ank, and a control sequence. Shown is 1 representative experiment of 3. (G) Femoral mRNA levels analyzed by qRT-PCR. $n=8 .{ }^{*} P<0.05$, ${ }^{\star *} P<0.01$, ${ }^{\#} P<0.001$ vs. vehicle-treated $V d r^{+/+}, 1$-way ANOVA followed by Fisher's LSD multiple-comparison test; $\$ \S P<0.01, \S \S \S P<0.001$ vs. Vdrint+.

Hydroxyapatite crystal expansion is controlled by the PPi/inorganic phosphate $(\mathrm{PPi} / \mathrm{Pi}$ ) balance, with $\mathrm{PPi}$ being the suppressor of crystal growth. We observed that $1,25(\mathrm{OH})_{2} \mathrm{D}_{3}$-mediated suppression of mineralization was largely dependent on increased PPi levels. Addition of $1,25(\mathrm{OH})_{2} \mathrm{D}_{3}$ to cultured mature primary osteoblasts or an osteoblastic cell line suppressed their mineralization, and this effect was associated with increased PPi levels (Figure 6 and Supplemental Figure 5, D and E). This $1,25(\mathrm{OH})_{2} \mathrm{D}_{3}$-mediated suppression of mineralization was rescued when PPi levels were lowered by cotreatment of the cells with tissue-nonspecific alkaline phosphatase (TNAP; also known as ALPL) (Figure 6 and Supplemental Figure $5 \mathrm{~F}$ ), which indicated that the inhibitory effect of $1,25(\mathrm{OH})_{2} \mathrm{D}$ on mineralization results from increased PPi levels.

Extracellular PPi levels are regulated by multiple proteins: PPi is generated from NTP in matrix vesicles by ectonucleotide pyrophosphatase phosphodiesterase 1 (ENPP1) and in the lumen of the endoplasmic reticulum by ENPP3; progressive ankylosis (ANK) transports PPi to the extracellular environment; and TNAP hydrolyses, and thereby inactivates, $\mathrm{PPi}(11) .1,25(\mathrm{OH})_{2} \mathrm{D}$ regulated PPi levels by controlling the transcription of several of these genes. The $1,25(\mathrm{OH})_{2} \mathrm{D}_{3}$-mediated increase in PPi levels in osteoblastic cells in vitro was associated with upregulated mRNA levels of Enpp1, Enpp3, and Ank and a tendency toward reduced Tnap mRNA levels, but only when the VDR was functional (Figure 7, A-D). In addition, ChIP-deep sequencing (ChIP-seq) analysis revealed $\mathrm{VDR} / \mathrm{RXR}$ binding $+58 \mathrm{~kb}$ downstream of the Enpp3 promoter, which was confirmed by quantitative real-time RT-PCR (qRTPCR) analysis (Figure 7, E and F). A luciferase reporter assay confirmed that $1,25(\mathrm{OH})_{2} \mathrm{D}_{3}$ was able to activate transcription from this region (Supplemental Figure 5G). Together, these results suggest that $1,25(\mathrm{OH})_{2} \mathrm{D}_{3}$ may stimulate gene transcription of Enpp3 and/or the downstream Enpp1, possibly via a vitamin D respon- 

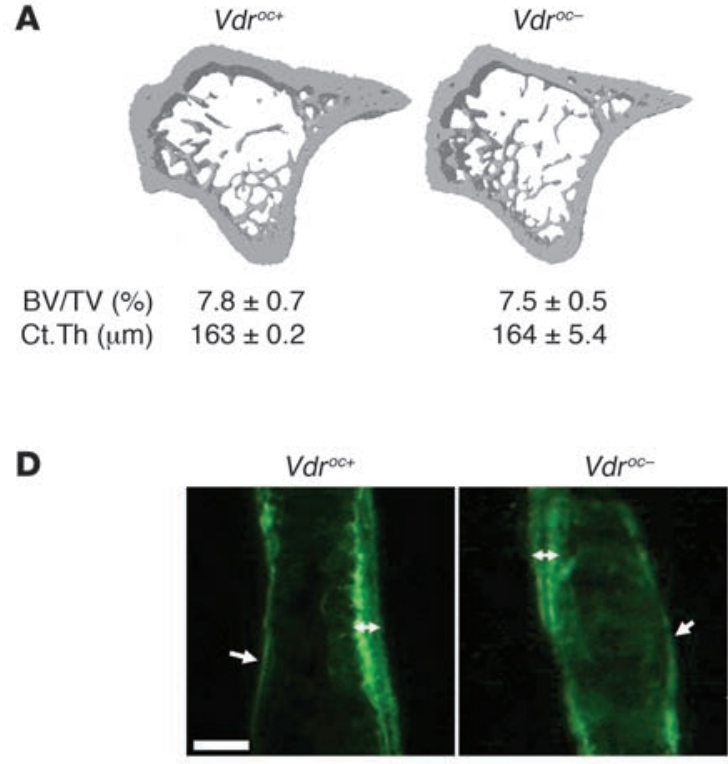

MAR $(\mu \mathrm{m} / \mathrm{d}) \quad 2.87 \pm 0.3$ MS (\%) $\quad 37.5 \pm 5.7$

$\operatorname{BFR}\left(\mu \mathrm{m}^{3} / \mu \mathrm{m}^{2} / \mathrm{d}\right) \quad 1.11 \pm 0.2$

$.65 \pm 0.2$

$28.6 \pm 2.3$

$0.81 \pm 0.3$

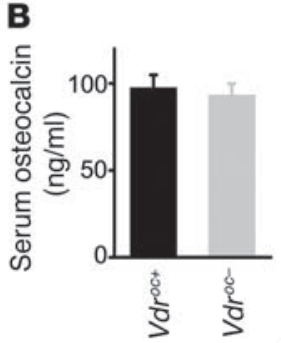

C
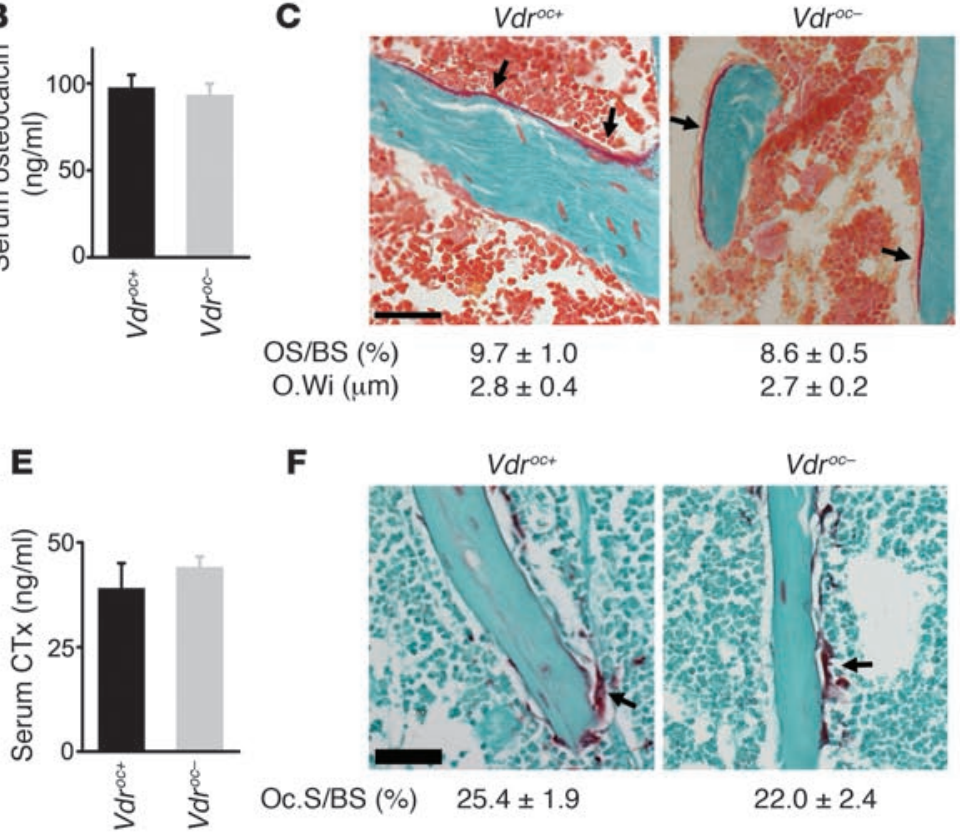

$\mathbf{F}$
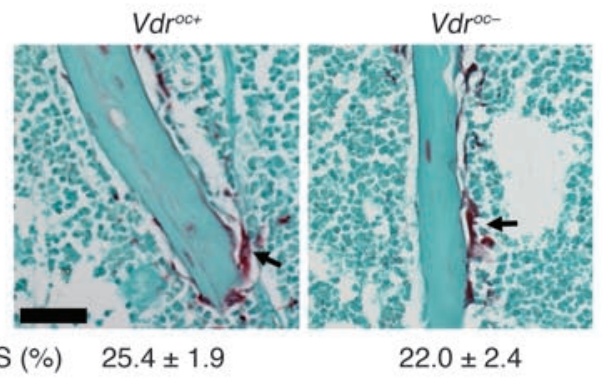

\section{Figure 8}

Normal bone homeostasis in Vdroc- mice. (A) Cross-sectional 3D $\mu \mathrm{CT}$ images of the tibia with quantification of BV/TV and Ct.Th. $n=8$. (B) Serum osteocalcin levels. $n=8$. (C) Goldner-stained trabeculae (arrows denote osteoids) with quantification of osteoid surface and thickness. $n=5$. Scale bar: $50 \mu \mathrm{m}$. (D) Analysis of dynamic bone formation parameters by sequential calcein injections showing the presence of single (arrow) and double (double-sided arrow) labels and quantification of the mineral apposition rate (MAR), mineralizing surface (MS), and bone formation rate (BFR) in the trabecular area. $n=5$. Scale bar: $20 \mu \mathrm{m}$. (E) Serum CTx levels. $n=4-6$. (F) TRAP staining showing osteoclasts (arrow) on the trabeculae and quantification of the osteoclast surface (Oc.S/BS). $n=5$. Scale bar: $50 \mu \mathrm{m}$.

sive element (VDRE) within Enpp3. Similarly, ChIP-seq and qRTPCR data showed VDR/RXR binding $+63 \mathrm{~kb}$ downstream of the transcriptional start site (TSS) of Ank, and this region mediated $1,25(\mathrm{OH})_{2} \mathrm{D}_{3}$-responsive gene transcription. The TSS also showed a small amount of VDR/RXR binding by qRT-PCR, but we were unable to confirm its activity (Figure 7F and Supplemental Figure $5 \mathrm{G})$. Thus, $1,25(\mathrm{OH})_{2} \mathrm{D}_{3}$ increased PPi levels by regulating the proteins involved in PPi metabolism, and this system played an important role in the suppression of mineralization by $1,25(\mathrm{OH})_{2} \mathrm{D}_{3}$.

Consistent with the in vitro findings, the skeletal mineralization defects of $V d r^{i n t-}$ mice were associated with upregulated Ank and Enpp3 levels (Figure 7G) and an increased PPi/Pi ratio $\left(V d r^{i n t+}, 0.54 \% \pm 0.05 \% ; V d r^{i n t-}, 0.70 \% \pm 0.07 \% ; n=4\right)$. Conversely, in $V d r^{-/}$bones, Enpp1 expression was decreased and Tnap levels were increased (Supplemental Figure $5 \mathrm{H}$ ), suggestive of a reverse effect when VDR is lacking: reduced production and enhanced degradation of PPi.

In addition, $1,25(\mathrm{OH})_{2} \mathrm{D}_{3}$ is known to induce gene expression of the mineralization inhibitor Opn, via binding of the VDR to regulatory sequences directly upstream of the Opn promoter (ref. 12 and Figure 7H). Accordingly, Opn mRNA was significantly increased in femora of $V d r^{\text {int }}$ - mice, whereas no significant change was observed in bones of $\mathrm{Vdr}^{-1}$ mice (Figure $7 \mathrm{G}$ and Supplemental Figure 5H). mRNA levels of phosphate-regulating gene with homologies to endopeptidases on the $\mathrm{X}$ chromosome (Phex; encoding a protein suggested to cleave and inactivate OPN; ref. 13) were decreased in $V d r^{\text {int }}$ femora; a similar trend was observed in osteoblastic cells treated with $1,25(\mathrm{OH})_{2} \mathrm{D}_{3}$ (Figure $7, \mathrm{G}$ and I). These findings may suggest enhanced production and impaired degradation of OPN. The addition of $2.5 \times 10^{-8} \mathrm{M}$ PTH significantly decreased Phex levels (Figure 7I), which suggests that the high PTH levels in $V d r^{\text {int }}$ - mice may also contribute to the reduced Phex levels. Notably, PTH tended to decrease Opn levels in cultured osteoblastic cells (Figure $7 \mathrm{H}$ ), and therefore cannot account for the increased Opn levels observed in vivo. Thus, the $1,25(\mathrm{OH})_{2} \mathrm{D}_{3}$-induced increase of Opn gene expression may contribute to the $1,25(\mathrm{OH})_{2} \mathrm{D}$-mediated suppression of bone matrix mineralization. The expression of other known mineralization inhibitors, including Dmp1, Mgp, and Phospho1, was not altered in femora of $V d r^{\text {int }}$ mice (data not shown). Taken together, these observations suggest that impaired skeletal mineralization in $V d r^{\text {int }}$ mice results from increased abundance of mineralization inhibitors, mediated by excessive VDR signaling. More specifically, we conclude that $1,25(\mathrm{OH})_{2} \mathrm{D}$ directly controls the gene expression of the SIBLING protein Opn and of several enzymes involved in PPi metabolism, including Enpp3 and Ank.

Increased VDR signaling in mature osteoblasts/osteocytes is required to suppress bone mineralization and shift calcium from bone to serum. To confirm that osteoblastic VDR signaling is involved in mobilizing calcium from bone, we specifically and efficiently inactivated $V d r$ expression in the late osteoblastic lineage ( $V d r^{o c-}$ mice; Supplemental Figure 6A). As expected, serum calcium, phosphate, and $1,25(\mathrm{OH})_{2} \mathrm{D}$ levels; bone mass; bone remodeling; and osteoblast and osteocyte differentiation were not altered in $V d r^{\circ-}$ mice fed a normal calcium diet ( $1 \%$ calcium) (Figure 8 and Supplemental 

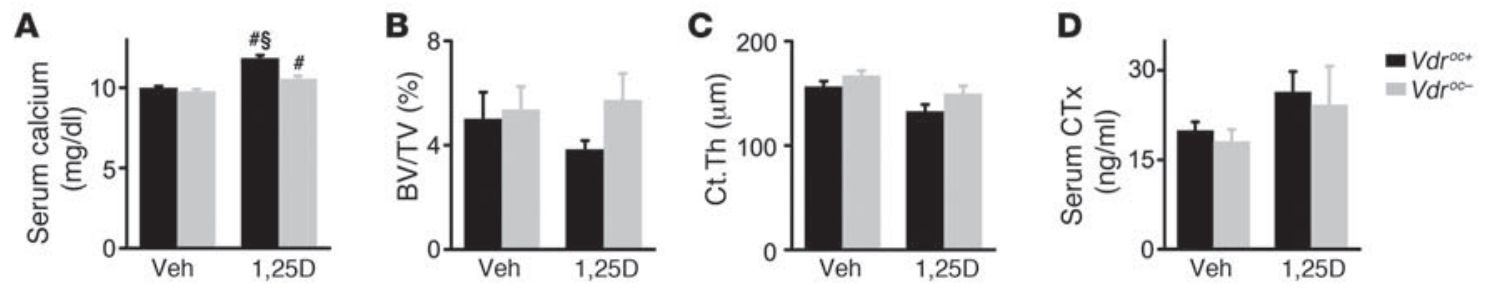

E

$$
\mathbf{F}
$$
Veh
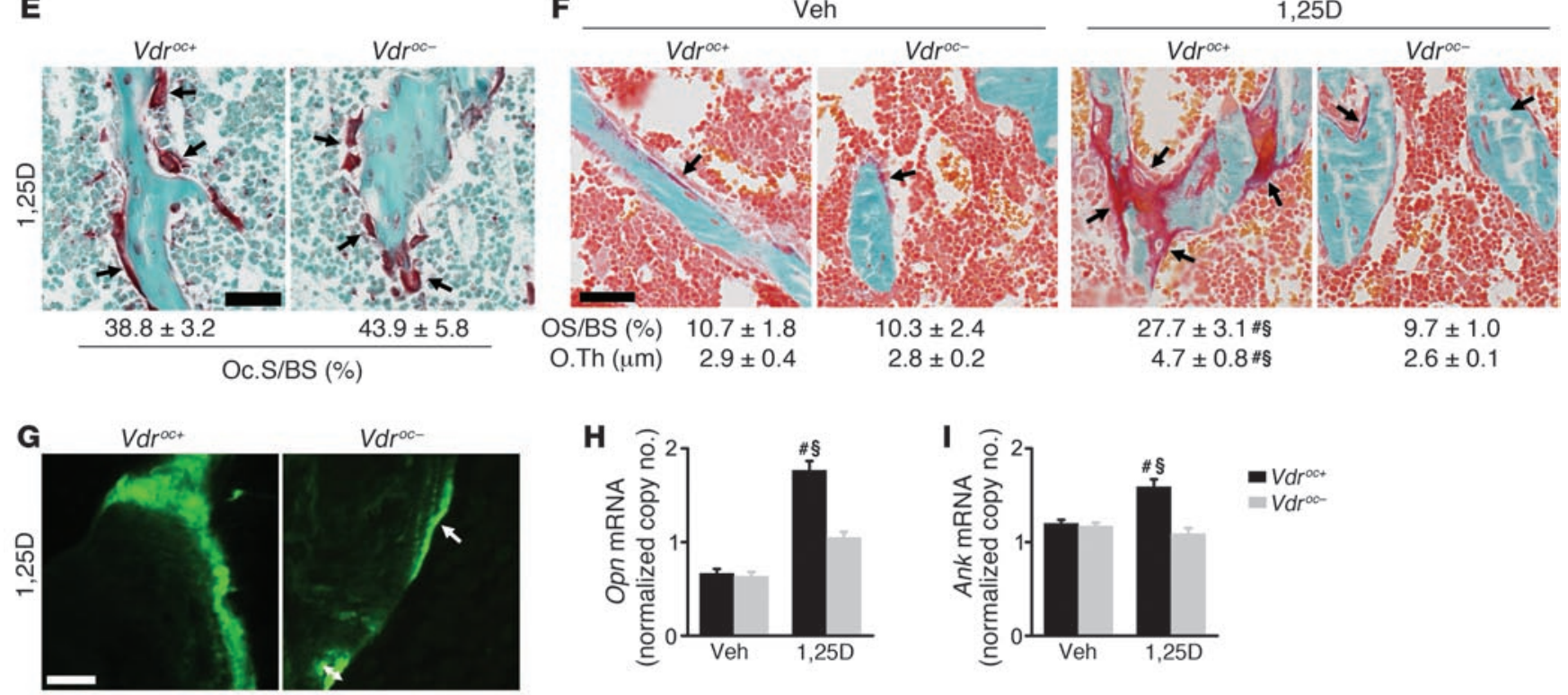

Figure 9

Vdroc- mice are protected against $1,25(\mathrm{OH})_{2} \mathrm{D}_{3}$-induced mineralization defects. Vdroc+ and Vdroc- mice were treated with vehicle or $1,25(\mathrm{OH})_{2} \mathrm{D}_{3}$ for 1 week. (A) Serum calcium levels. $n=4-6$. (B and C) $\mu$ CT analysis of BV/TV (B) and Ct.Th (C). $n=8$. (D) Serum CTx levels. $n=4-6$. (E) TRAP staining showing osteoclasts (arrows) on the trabeculae and quantification of the osteoclast surface. $n=5$. Scale bar: $50 \mu \mathrm{m}$. (F) Goldner-stained trabeculae (arrows denote osteoids) with quantification of osteoid surface and thickness. $n=5$. Scale bar: $50 \mu \mathrm{m}$. (G) Analysis of dynamic bone formation parameters by sequential calcein injections showing a normal mineralization pattern in Vdroc- mice with the formation of single (arrow) and double (double-sided arrow) labels. Scale bar: $20 \mu \mathrm{m}$. (H and I) mRNA expression in the femur analyzed by qRT-PCR. $n=5-8$. Values denote mRNA copy number normalized to that of $H p r t$ (see Methods). ${ }^{\prime} P<0.05,1,25(\mathrm{OH})_{2} \mathrm{D}_{3}$ vs. vehicle, ${ }^{\S} P<0.05, \mathrm{Vdr}{ }^{\circ-} \mathrm{vs}$. Vdroc+, 2-way ANOVA followed by Fisher's LSD multiple-comparison test.

Figure 6, B-I). Thus, we concluded that VDR signaling in mature osteoblasts/osteocytes is redundant for calcium and bone homeostasis when sufficient dietary calcium is absorbed.

To address the consequences of increased $1,25(\mathrm{OH})_{2} \mathrm{D}$ action on the skeleton, $V d r^{o c+}$ and $V d r^{o c-}$ mice were treated with $1,25(\mathrm{OH})_{2} \mathrm{D}_{3}$ for 1 week. 1,25(OH $)_{2} \mathrm{D}_{3}$-induced hypercalcemia was markedly less pronounced in $V d r^{o c}$ mice, with a clear tendency for better preservation of bone mass compared with $\mathrm{Vdr}^{\text {oct }}$ mice (Figure 9, A-C). As we postulated, $1,25(\mathrm{OH})_{2} \mathrm{D}$ shifted calcium from bone to serum by stimulating bone resorption, as evidenced by a nonsignificant increase in serum CTx levels and a profound increase in the abundance of osteoclasts compared with untreated mice (Figure $8 \mathrm{~F}$ ). Surprisingly, the increase in these parameters was not different between genotypes (Figure 9, D and E). A possible explanation is that VDR signaling in the early osteoblasts is sufficient to account for the $1,25(\mathrm{OH})_{2} \mathrm{D}$-induced bone resorption.

However, the similar increase in bone resorption cannot explain the less-profound hypercalcemia in $V d r^{\text {oc- }}$ mice, which strengthens the concept that $1,25(\mathrm{OH})_{2} \mathrm{D}$ can increase blood calcium levels by suppressing bone matrix mineralization. Indeed,
$1,25(\mathrm{OH})_{2} \mathrm{D}_{3}$ treatment induced marked hyperosteoidosis and impaired matrix mineralization in $V d r^{o c+}$ mice only, not in $V d r^{o c-}$ mice, as evidenced by Goldner staining and defective calcein incorporation (Figure 9, F and G, and Supplemental Figure 6, J and K). Accordingly, femoral mRNA levels of Opn and Ank were increased in $1,25(\mathrm{OH})_{2} \mathrm{D}_{3}$-treated $V d r^{o c+}$ mice. Importantly, $V d r$ inactivation in the osteoblastic lineage completely prevented the mineralization defects and the increase in mineralization inhibitors (Figure 9, H and I, and Supplemental Figure $6 \mathrm{~L})$. Notably, we did not detect a genotype-related differential effect of $1,25(\mathrm{OH})_{2} \mathrm{D}_{3}$ action on serum osteocalcin levels and markers for osteoblast differentiation (Supplemental Figure 6, $\mathrm{M}$ and $\mathrm{N}$ ). The comparable intestinal calcium absorption and urinary calcium loss between genotypes, evidenced by similar mRNA levels of intestinal calcium transporters and urinary calcium levels (Supplemental Figure 6, O-Q), could also not explain why $1,25(\mathrm{OH})_{2} \mathrm{D}_{3}$ treatment primarily induced hypercalcemia in $V d r^{\text {oct }}$ mice. Together, these data showed that mineralization defects developed only in $1,25(\mathrm{OH})_{2} \mathrm{D}_{3}$-treated $V d r^{\text {oct }}$ mice, which indicates that increased VDR signaling in the late osteoblastic 
A

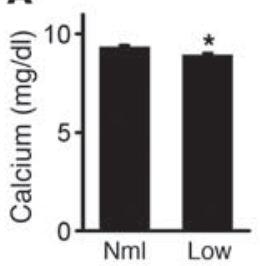

E

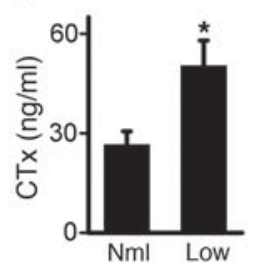

B

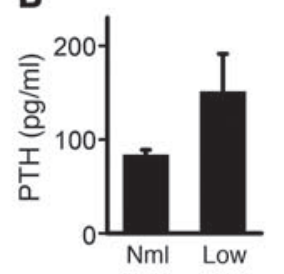

$\mathbf{F}$

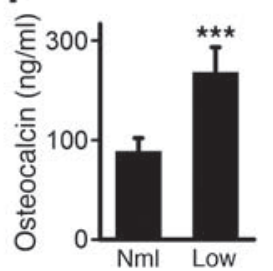

C

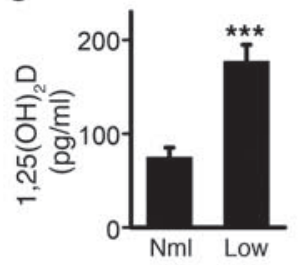

G

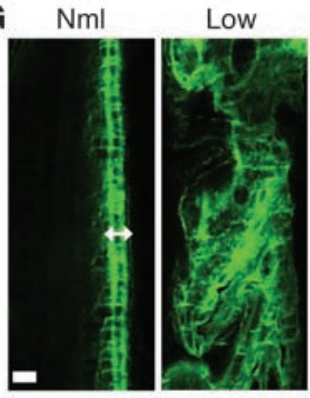

D

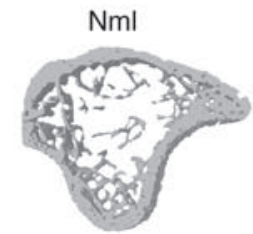

BV/TV (\%) $\quad 10.4 \pm 1.4$ Ct.Th $(\mu \mathrm{m}) \quad 122 \pm 3.9$

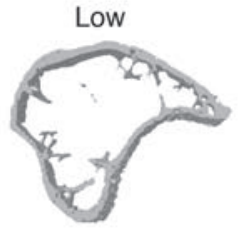

$5.9 \pm 0.7 * \star$

$82 \pm 1.7^{\star \star \star \star}$
H

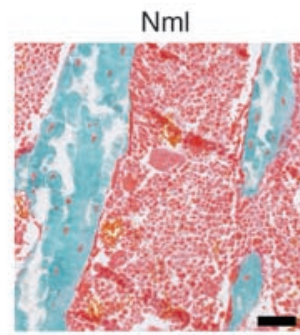

OS/BS (\%) $\quad 27.7 \pm 1.4$

O.Th $(\mu \mathrm{m}) \quad 2.68 \pm 0.11$

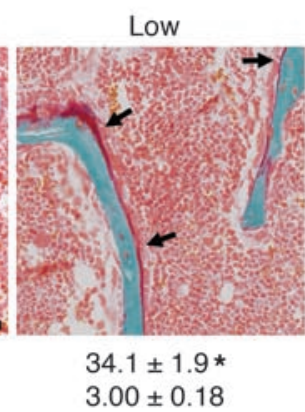

I

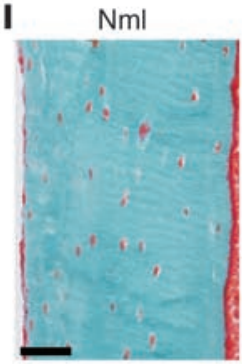

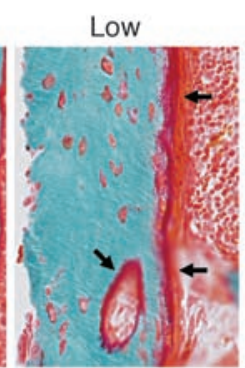

J

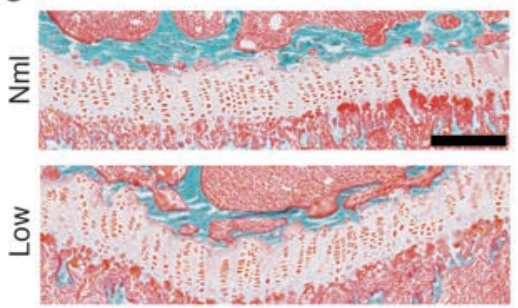

K

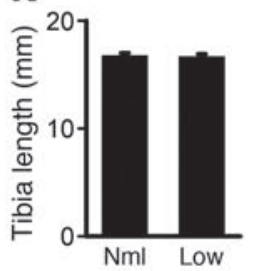

L

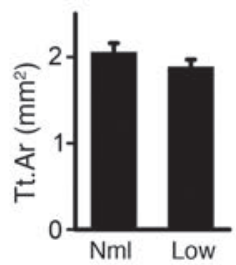

Figure 10

Dietary calcium restriction after weaning mimics the Vdrint- phenotype. Vdrint+ mice were fed a normal (Nml) or low-calcium (Low) diet. (A-C, E, and F) Serum calcium (A), PTH (B), 1,25(OH) 2 D (C), CTx (E), and osteocalcin (F) levels. $n=6-8$. (D) Quantitative $\mu$ CT analysis of the tibia. $n=6-8$. (G) Histological image of the diaphyseal cortices after sequential calcein injection showing a normal mineralization pattern in $V d r^{\text {ritt }}+$ mice fed a normal diet, demonstrated by the double label formation (double-sided arrow). Scale bar: $10 \mu \mathrm{m}$. (H and I) Visualization of osteoid (arrows) on the trabeculae (H) and cortical surfaces (I) by Goldner staining. Quantification of osteoid surface and thickness is also shown in $\mathbf{H}$. $n=6$. Scale bar: $50 \mu \mathrm{m}$. (J) Goldner staining of the growth plate. Scale bar: $200 \mu \mathrm{m}$. (K) Length of the tibia. $n=6-7$. (L) Quantification of the cross-sectional area of the tibia by $\mu \mathrm{CT} . n=6-8 .{ }^{*} P<0.05,{ }^{* *} P<0.01,{ }^{* \star *} P<0.001 \mathrm{vs}$. normal diet.

lineage impairs bone matrix mineralization by increasing the expression of mineralization inhibitors.

$1,25(\mathrm{OH})_{2} \mathrm{D}$-mediated intestinal calcium absorption is crucial for surviving calcium restriction. The $1,25(\mathrm{OH})_{2} \mathrm{D}$-mediated pathway of intestinal calcium transport gains importance when dietary calcium levels decline. As our findings revealed that intestinal VDR activity was already crucial to preserve skeletal integrity during normal calcium intake $(\sim 1 \%)$, we wondered how calcium and bone homeostasis would adapt during calcium restriction, when intestinal VDR activity is lacking. $V d \gamma^{\text {int }}$ mice were therefore fed a low-calcium $\operatorname{diet}(\sim 0.02 \%)$ from weaning on. Within 14 days of starting the diet, 8 of $16 \mathrm{Vdrint-}$ mice (50\%) died. The surviving Vdrint- mice (4.5 weeks old) were hypocalcemic (serum calcium, $7.0 \pm 0.3 \mathrm{mg} / \mathrm{dl} ; n=6$ ) and developed even more pronounced osteopenia compared with age-matched $V d r^{\text {int }}$ mice on the normal calcium diet (low calcium, $1.55 \% \pm 0.4 \% \mathrm{BV} / \mathrm{TV}$, $43 \pm 2.0 \mu \mathrm{m}$ Ct. Th; normal calcium, $2.6 \% \pm 0.4 \% \mathrm{BV} / \mathrm{TV}, 70.0 \pm 6.4$ $\mu \mathrm{m} \mathrm{Ct.Th} ; P<0.05$ for BV/TV, $P<0.001$ for Ct.Th; $n=6$ ). Thus, when calcium malabsorption was extreme, the skeletal responses became insufficient, resulting in hypocalcemia and early lethality.
As expected, $V d r^{\text {int }}$ littermates fed the low-calcium diet survived normally and mimicked the Vdrint- phenotype. More precisely, normal serum calcium levels were maintained, serum levels of the calciotropic hormones were increased, and bone mass accrual was reduced and characterized by increased bone remodeling and decreased bone mineralization. Bone growth, on the other hand, was normal (Figure 10 and Supplemental Figure 7, A-C). These observations indicated that both intestinal $V d r$ deletion and dietary calcium restriction, as means of compromising active intestinal calcium absorption, have similar effects on calcium and bone homeostasis.

Intestinal calcium absorption is less dependent on $1,25(\mathrm{OH})_{2} \mathrm{D}$ action when the diet is rich in calcium. Consequently, we found that feeding $V d r^{\text {int }}$ - mice a high-calcium rescue diet prevented the $V d r^{\text {int }}$ phenotype completely, including the changes in calciotropic hormones, urinary calcium excretion, and skeletal phenotype (Supplemental Figure 7, D-L).

We conclude from the present studies that the hormonal and skeletal abnormalities associated with intestinal $V d r$ deletion are caused by reduced intestinal calcium absorption. Moreover, 


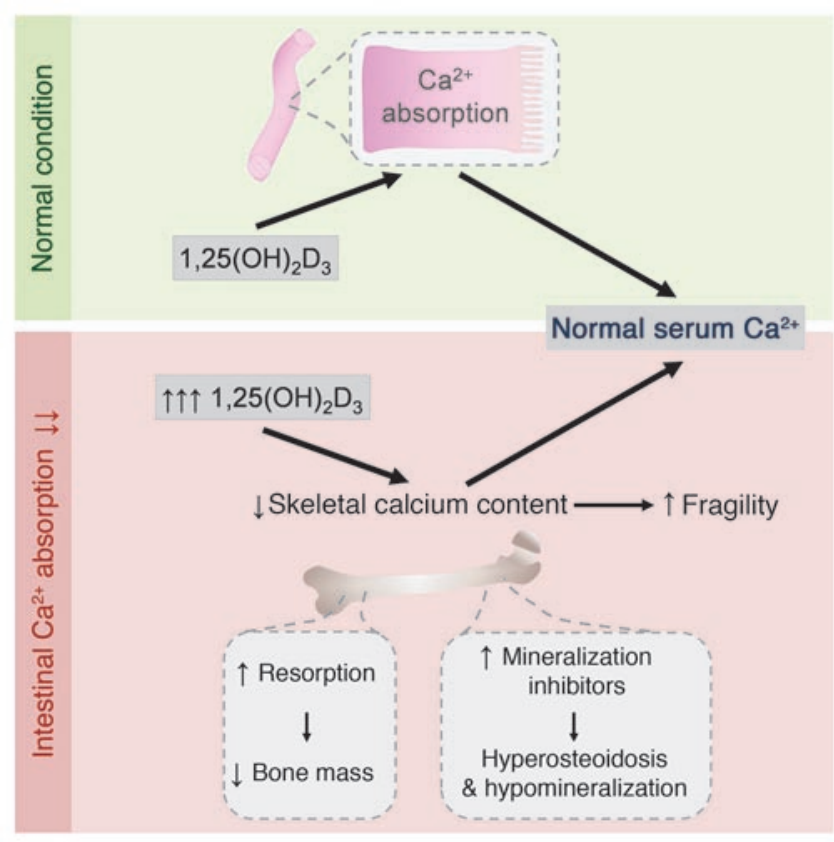

Figure 11

$1,25(\mathrm{OH})_{2} \mathrm{D}$ induces skeletal hypomineralization and osteopenia to preserve serum calcium. During normal calcium intake, stimulation of intestinal calcium absorption by $1,25(\mathrm{OH})_{2} \mathrm{D}$ is important to prevent a negative calcium balance. When dietary calcium supply is low or intestinal calcium absorption is hampered, $1,25(\mathrm{OH})_{2} \mathrm{D}$ levels increase and preserve normocalcemia by stimulating, together with $\mathrm{PTH}$, bone resorption and by upregulating mineralization inhibitors, thus reducing bone matrix mineralization. These skeletal adaptations are essential to secure the processes that depend on normal serum calcium levels, but are deleterious for skeletal integrity.

$1,25(\mathrm{OH})_{2} \mathrm{D}$-mediated intestinal calcium transport is already essential for the preservation of skeletal integrity during normal calcium intake, and it becomes indispensible to guarantee survival during calcium restriction.

\section{Discussion}

Calcium stored in bone can be redistributed to serum when the calcium balance is negative, but to date, the skeletal adaptations and molecular mediators were still largely unknown. Here, we found that the shift of calcium from bone to serum depended on the control of calcium incorporation into the bone matrix as well as calcium release from bone, and that $1,25(\mathrm{OH})_{2} \mathrm{D}$ was a prime regulator of both processes. These data suggest that the cellular processes regulated by serum calcium will be guaranteed at the expense of skeletal integrity, even when these adaptations result in bone fractures.

Insufficient intestinal calcium absorption caused by dietary restriction or intestinal-specific $V d r$ inactivation ( $V d r^{\text {int- }}$ mice) resulted in a negative calcium balance. Increased renal calcium reabsorption, mediated by the high levels of PTH and $1,25(\mathrm{OH})_{2} \mathrm{D}$ (data not shown), may partially counterbalance the impaired intestinal calcium absorption in $V d r^{\text {int- }}$ mice. In addition, skeletal calcium can supply the serum calcium pool by 2 distinct, complementary mechanisms. As generally accepted, calcium is released by an increase in bone resorption in response to elevated PTH and $1,25(\mathrm{OH})_{2} \mathrm{D}$ levels, leading to decreased bone mass. In theory, inhibiting bone matrix mineralization may represent an additional beneficial process to safeguard normocalcemia. We here provide evidence that both processes constitute the skeletal response to inadequate intestinal calcium absorption.

Shortly after weaning, when $1,25(\mathrm{OH})_{2} \mathrm{D}$-mediated intestinal calcium transport becomes important, PTH and $1,25(\mathrm{OH})_{2} \mathrm{D} \mathrm{lev-}$ els increased in $V d r^{i n t-}$ mice. These hormonal changes likely caused the extensive cortical remodeling and high bone turnover that are present from that moment on (14). An argument against PTH being involved is our observation that PTH was also increased in $V d r^{--}$mice, but that bone mass was better preserved and cortical remodeling was less pronounced in $V d r^{-1}$ than in $V d r^{\text {int- }}$ mice. However, it is possible that $V d r^{-1}$ mice develop skeletal resistance to $\mathrm{PTH}$, as is often observed in response to prolonged exposure to extremely high PTH levels (14). This unresponsiveness to PTH may also be present in $V d r^{\text {int }}$ mice, although probably less prominent, because the PTH levels are only modestly increased (1.3-fold vs. 10-fold in $\mathrm{Vdr}^{-/}$mice; ref. 9). In addition, the PTH and VDR signaling pathways are regarded to be interdependent, and the lack of VDR expression in bone cells of $\mathrm{Vdr} r^{-/}$mice may thus hinder the response to PTH (15). Further studies are required to investigate the interaction between PTH and VDR signaling in these settings. Together, our findings indicate that a reduction in mineralized bone mass, via increased bone remodeling by PTH and/or $1,25(\mathrm{OH})_{2} \mathrm{D}$, is a first mechanism to transfer calcium from bone to serum.

We argue that the inhibition of calcium incorporation in bone is equally important to preserve serum calcium levels and that the increased $1,25(\mathrm{OH})_{2} \mathrm{D}$ levels are critical to redirect skeletal calcium toward serum. Indeed, only when increased $1,25(\mathrm{OH})_{2} \mathrm{D}$ levels could elicit a skeletal response [i.e., in $V d r^{\text {int- }}$ mice, $1,25(\mathrm{OH})_{2} \mathrm{D}$ treated $V d r^{o c t}$ mice, and $V d r^{i n t+}$ mice receiving a low-calcium diet, but not in $V d r^{/-}$or $V d r^{o c-}$ mice] was bone matrix mineralization inhibited, and was a profound shift of calcium from bone to serum observed. In agreement with this finding, bone fractures that are associated with dietary calcium restriction in growing rats are prevented when the low-calcium diet is combined with vitamin D deficiency, but the latter condition is associated with more pronounced hypocalcemia (4). Several lines of evidence support our finding that increased $1,25(\mathrm{OH})_{2} \mathrm{D}$ serum levels suppresses bone matrix mineralization. Supraphysiological vitamin D levels in humans (8) and animals (present study and ref. 16) result in osteoid excess, which we prevented here by inactivating osteoblastic $V d r$ signaling in mice. Other mouse models, including Cyp24-null (17) and Fgf23null (18) mice, show deregulated vitamin D homeostasis, characterized by inappropriately high $1,25(\mathrm{OH})_{2} \mathrm{D}$ levels with consequently low PTH and hypercalcemia, and display reduced mineralized bone mass and hyperosteoidosis. The inhibitory effects of $1,25(\mathrm{OH})_{2} \mathrm{D}$ on mineralization were also confirmed by in vitro experiments on several mouse and rat osteoblastic cell lines and by the increased mineralization observed in $\mathrm{Vdr}^{-/}$osteoblasts (present study and ref. 7). Here, we provide evidence that increased $1,25(\mathrm{OH})_{2} \mathrm{D}$ levels restrained bone mineral incorporation, which led to the observed mineralization defects. This system contributes to the physiological adaptations that compensate for calcium malabsorption and are directed at maintaining normocalcemia.

Mechanistically, $1,25(\mathrm{OH})_{2} \mathrm{D}$ suppressed mineralization by regulating gene transcription of several mineralization inhibitors. It is well documented that the mineralization inhibitor $O p n$ is a 
$1,25(\mathrm{OH})_{2} \mathrm{D}$-responsive gene (12). Another important mineralization inhibitor is PPi, which is generated by ENPP1 and ENPP3, transported extracellularly by ANK, and inactivated by TNAP. The physiological relevance of abnormal PPi metabolism in mineralization is underscored by the soft tissue calcifications and hypermineralized bone abnormalities in mice lacking Ank and Enpp1 activity; the in vivo significance of ENPP3 remains to be determined (19). However, it was still unknown how PPi levels are fine-tuned to regulate mineralization in bone and which factors control PPi levels. Our data showed that $1,25(\mathrm{OH})_{2} \mathrm{D}$ increased PPi levels via the transcriptional control of especially Ank and Enpp3 expression and that this mechanism played a crucial role in the $1,25(\mathrm{OH})_{2} \mathrm{D}$ mediated suppression of mineral incorporation. Together, these data suggest that regulation of PPi levels by $1,25(\mathrm{OH})_{2} \mathrm{D}$ is involved in the physiological response of the skeleton to a negative calcium balance. However, we recognize that the control of bone matrix mineralization in vivo is extremely complex (10) and that the described $1,25(\mathrm{OH})_{2} \mathrm{D}$-mediated regulation of several mineralization inhibitors does not exclude that other modulators and/or posttranslational modifications may also be involved.

In contrast to the severe reduction in bone mass and mineralization, skeletal growth was not hampered by calcium restriction. This finding supports the importance of normal serum calcium and especially phosphate levels for normal growth plate morphology and skeletal growth, but also implies that these processes are not negatively affected by hyperparathyroidism and increased $1,25(\mathrm{OH})_{2} \mathrm{D}$ levels (7). Bone growth and bone mass accrual are thus separately - although interdependently - regulated: $1,25(\mathrm{OH})_{2} \mathrm{D}$ (and PTH) ensure the preservation of serum calcium by minimizing calcium deposition in bone matrix, and the normocalcemia guarantees normal bone growth.

The phenotype of the $V d r^{i n t}$ mice underscores the importance of intestinal calcium absorption for bone homeostasis, a process that is often defective in patients with osteoporosis. This mouse model differs from the human situation in several aspects, namely, (a) the human diet will likely be less deficient in calcium; (b) elderly people are usually vitamin $\mathrm{D}$ deficient, and the high $1,25(\mathrm{OH})_{2} \mathrm{D}$ levels will therefore not occur unless vitamin $\mathrm{D}$ supplements are given without correction of the calcium deficiency; and (c) the effects on bone may be more pronounced in the mouse models as they were analyzed during growth. Based on our findings, we suggest caution with vitamin D supplementation without giving extra calcium, because this strategy may result in hypervitaminosis D that negatively affects bone quality. Our study may explain the surprising finding that vitamin D monotherapy increased fracture risk in 2 clinical trials; this outcome was associated with increased $1,25(\mathrm{OH})_{2} \mathrm{D}$ levels in the Smith study $(6,20)$. Together, these data advocate combined calcium-vitamin D therapy in the management of osteoporosis to optimize calcium acquisition and to prevent vitamin $\mathrm{D}$ toxicity that may develop, especially when calcium is insufficiently available.

In summary, our results showed that adequate intestinal calcium absorption is essential for normal bone mass accrual and that $1,25(\mathrm{OH})_{2} \mathrm{D}$ signaling is crucial to secure this process, even during normal calcium intake. When intestinal calcium transport is impaired, normocalcemia can be preserved by reducing the total amount of calcium stored in the skeleton, via a PTH- and VDR-mediated increase in bone remodeling, but equally well via a $1,25(\mathrm{OH})_{2} \mathrm{D}$-mediated reduction in bone mineralization (Figure 11). Conservation of normocalcemia is thus preferred over calcium storage in bone, a finding that should be kept in mind in the prevention and treatment of osteoporosis.

\section{Methods}

Animals. Generation of $V d r^{f / f l}$ and $V d r$-null mice was reported previously (9). $V d r^{l / f l}$ mice were crossed with transgenic mice expressing Cre recombinase under the control of the Villin gene promoter (21), generating Vil-

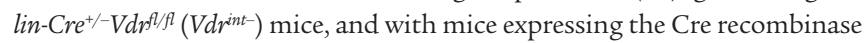
controlled by the $10-\mathrm{kb}$ fragment of the $D m p 1$ promoter (22), generating Dmp1-Cre ${ }^{+/-} V d r^{f l / f l}\left(V d r^{o-}\right)$ mice. $V d r^{+/+}$, Villin-Cre $e^{-/-} V d r^{f / f l}\left(V d r^{i n t+}\right)$, and Dmp1$C r e^{-/-} V d r^{f l / f l}\left(V d r^{0 c+}\right)$ littermates served as respective controls for $V d r^{-/}, V d r^{\text {int }}$, and $V d r^{o c-}$ animals. Mice had unlimited access to water and a standard rodent diet (1.0\% calcium, $0.7 \%$ phosphate; Ssniff R/M-H) and were examined at 8 weeks of age unless otherwise indicated (see Supplemental Methods for details). The following treatment regimens were used: (a) 8-week-old mice were s.c. injected with zoledronic acid $(100 \mu \mathrm{g} / \mathrm{kg} \mathrm{BW} / \mathrm{wk}$; provided by Novartis) for 6 weeks and sacrificed at 14 weeks of age. (b) 7 -week-old mice were i.p. injected with $1,25(\mathrm{OH})_{2} \mathrm{D}_{3}(0.5 \mu \mathrm{g} / \mathrm{kg} \mathrm{BW} / \mathrm{d})$ for 1 week and sacrificed 20 hours after the last injection. (c) Weanling mice received a lowcalcium diet ( $0.02 \%$ calcium, $0.7 \%$ phosphorus; 4403.06 custom-made diet; ABDiets) and were compared with littermates on an isoenergetic control diet (1\% calcium, 0.7\% phosphorus; 4403.05 custom-made diet; ABDiets). $V d r^{\text {intt }}$ mice were sacrificed at 8 weeks of age, and surviving $V d r^{\text {int }}$ - mice at 4.5 weeks of age. (d) Weanling mice received a rescue diet (2\% calcium, $1.25 \%$ phosphorus, 20\% lactose; TD96348; Harlan) for 5 weeks. Intestinal $\mathrm{Ca}^{2+}$ absorption was assessed in 8 -week-old mice by measuring serum ${ }^{45} \mathrm{Ca}^{2+}$ at early time points after oral gavage, as described previously (9).

Molecular analysis. Gene expression was analyzed with the primers and probes listed in Supplemental Table 1 and normalized for hypoxanthineguanine phosphoribosyltransferase (Hprt) expression. To determine genomic binding of VDR and RXR, MC3T3-E1 cells were treated with vehicle or $10^{-7} \mathrm{M} 1,25(\mathrm{OH})_{2} \mathrm{D}_{3}$ for 3 hours prior to ChIP using VDR, RXR, and nonspecific IgG antibodies, as described previously (23), followed by ChIP-seq or qRT-PCR. See Supplemental Methods for details.

In vitro osteoblast cultures. Primary osteoblasts were isolated as described previously (24). After osteoblastic differentiation $(50 \mu \mathrm{g} / \mathrm{ml}$ ascorbic acid and $10 \mathrm{mM} \beta$-glycerophosphate [Sigma-Aldrich, osteogenic medium]) for 6 days, cells were treated with $10^{-8} \mathrm{M} 1,25(\mathrm{OH})_{2} \mathrm{D}_{3}, 2.5 \times 10^{-8} \mathrm{M}$ hPTH(1-34) (Bachem), $5 \times 10^{-6} \mathrm{M}$ PPi (Sigma-Aldrich), and $1 \mathrm{U} / \mathrm{ml}$ TNAP (Sigma-Aldrich). Medium was collected to quantify PPi levels and normalized to the amount of DNA; cells were used for RNA and DNA extraction or were stained for Alizarin red. All quantifications were performed on 2-3 wells per condition and repeated 2-4 times.

Quantification of PPi levels. PPi levels in conditioned medium were determined as previously described (25). The PPi/Pi ratio in bone was quantified using a method adapted from that of Cho et al. (26). Briefly, the metaphyseal cortex of 8-week-old mice was isolated, cleaned, and immersed in $0.5 \mathrm{M}$ EDTA ( $\mathrm{pH}$ 7.5) for 2 weeks. High-resolution 31-P nuclear magnetic resonance spectroscopy in a $9.4 \mathrm{~T}$ vertical magnet (Bruker) at $188 \mathrm{Mhz}$ was performed on the EDTA solution, and the PPi/Pi signal intensity ratio was quantified using Topspin 2.1 (Bruker) without correction for saturation.

Statistics. Data are expressed as mean \pm SEM. To assess the effect of genotype or treatment, data were compared using 2-tailed Student's $t$ test. For multiple comparisons, Fisher's least significant difference (LSD) test was performed after ANOVA. Differences were considered significant for $P$ values less than 0.05 .

Study approval. All animals were treated according to the National Institutes of Health Guide for the Care and Use of Laboratory Animals, and all experiments were approved by the Ethical Committee Animal Tests of the University of Leuven. 


\section{Acknowledgments}

We are grateful to Novartis for zoledronic acid and to E. Van Herck, I. Jans, and W. Coopmans for serum analysis. We also thank I. Stockmans and K. Moermans for skillful technical assistance and T.J. Martin and I.R. Reid for critical reading of the manuscript. This work was supported by grants from the Fund for Scientific Research-Flanders (G.0508.05 and G.0587.09), the KU Leuven Center of Excellence (EF/05/08), and the NIH (DK-072281 and DK-073995). L. Lieben is a fellow of IWT Flanders.
Received for publication November 18, 2011, and accepted in revised form February 8, 2012.

Address correspondence to: Geert Carmeliet, Clinical and Experimental Endocrinology, Herestraat 49, O\&N1, bus 902, 3000 Leuven, Belgium. Phone: 32.16.330731; Fax: 32.16.330718; E-mail: geert.carmeliet@med.kuleuven.be.

Ritsuko Masuyama's present address is: Nagasaki University, Graduate School of Biomedical Sciences, Nagasaki, Japan.
1. Bouillon R, et al. Vitamin D and human health: lessons from vitamin D receptor null mice. Endocr Rev. 2008;29(6):726-776.

2. Yoshizawa T, et al. Mice lacking the vitamin D receptor exhibit impaired bone formation, uterine hypoplasia and growth retardation after weaning. Nat Genet. 1997;16(4):391-396.

3. Amling $\mathrm{M}$, et al. Rescue of the skeletal phenotype of vitamin D receptor-ablated mice in the setting of normal mineral ion homeostasis: formal histomorphometric and biomechanical analyses. Endocrinology. 1999;140(11):4982-4987.

4. Harrison M, Fraser R. Bone structure and metabolism in calcium-deficient rats. J Endocrinol. 1960; 21:197-205.

5. Tang BM, Eslick GD, Nowson C, Smith C, Bensoussan A. Use of calcium or calcium in combination with vitamin D supplementation to prevent fractures and bone loss in people aged 50 years and older: a metaanalysis. Lancet. 2007;370(9588):657-666.

6. Sanders KM, et al. Annual high-dose oral vitamin D and falls and fractures in older women: a randomized controlled trial. JAMA. 2010;303(18):1815-1822.

7. Bell TD, Demay MB, Burnett-Bowie SA. The biology and pathology of vitamin D control in bone. J Cell Biochem. 2010;111(1):7-13.

8. Adams JS, Lee G. Gains in bone mineral density with resolution of vitamin D intoxication. Ann Intern Med. 1997;127(3):203-206.

9. Van Cromphaut SJ, et al. Duodenal calcium absorption in vitamin D receptor-knockout mice: functional and molecular aspects. Proc Natl Acad Sci US A. 2001;98(23):13324-13329.

10. Golub EE. Role of matrix vesicles in biomineralization. Biochim Biophys Acta. 2009;1790(12):1592-1598.
11. Goding JW, Grobben B, Slegers H. Physiological and pathophysiological functions of the ectonucleotide pyrophosphatase/phosphodiesterase family. Biochim Biophys Acta. 2003;1638(1):1-19.

12. Meyer MB, Goetsch PD, Pike JW. Genome-wide analysis of the VDR/RXR cistrome in osteoblast cells provides new mechanistic insight into the actions of the vitamin D hormone. J Steroid Biochem Mol Biol. 2010;121(1-2):136-141.

13. Addison WN, Masica DL, Gray JJ, McKee MD. Phosphorylation-dependent inhibition of mineralization by osteopontin ASARM peptides is regulated by PHEX cleavage. J Bone Miner Res. 2010; 25(4):695-705

14. Fraser WD. Hyperparathyroidism. Lancet. 2009; 374(9684):145-158.

15. Galli C, et al. Targeted deletion of a distant transcriptional enhancer of the receptor activator of nuclear factor-kappaB ligand gene reduces bone remodeling and increases bone mass. Endocrinology. 2008; 149(1):146-153.

16. Wronski TJ, Halloran BP, Bikle DD, Globus RK, Morey-Holton ER. Chronic administration of 1,25-dihydroxyvitamin D3: increased bone but impaired mineralization. Endocrinology. 1986; 119(6):2580-2585.

17. St Arnaud R, et al. Deficient mineralization of intramembranous bone in vitamin D-24hydroxylase-ablated mice is due to elevated 1,25dihydroxyvitamin $\mathrm{D}$ and not to the absence of 24,25-dihydroxyvitamin D. Endocrinology. 2000; 141(7):2658-2666.

18. Shimada T, et al. Targeted ablation of Fgf23 demonstrates an essential physiological role of FGF23 in phosphate and vitamin D metabolism. J Clin
Invest. 2004;113(4):561-568.

19. Kornak U. Animal models with pathological mineralization phenotypes. Joint Bone Spine. 2011; 78(6):561-567.

20. Smith H, Anderson F, Raphael H, Maslin P, Crozier $\mathrm{S}$, Cooper C. Effect of annual intramuscular vitamin D on fracture risk in elderly men and womena population-based, randomized, double-blind, placebo-controlled trial. Rheumatology (Oxford). 2007; 46(12):1852-1857.

21. Madison BB, Dunbar L, Qiao XT, Braunstein K, Braunstein E, Gumucio DL. Cis elements of the villin gene control expression in restricted domains of the vertical (crypt) and horizontal (duodenum, cecum) axes of the intestine. J Biol Chem. 2002; 277(36):33275-33283.

22. Lu Y, Xie Y, Zhang S, Dusevich V, Bonewald LF, Feng JQ. DMP1-targeted Cre expression in odontoblasts and osteocytes. J Dent Res. 2007;86(4):320-325.

23. Meyer MB, Goetsch PD, Pike JW. A downstream intergenic cluster of regulatory enhancers contributes to the induction of CYP24A1 expression by 1alpha,25-dihydroxyvitamin D3. J Biol Chem. 2010; 285(20):15599-15610.

24. Masuyama R, et al. TRPV4-mediated calcium influx regulates terminal differentiation of osteoclasts. Cell Metab. 2008;8(3):257-265.

25. Johnson K, Moffa A, Chen Y, Pritzker K, Goding J, Terkeltaub R. Matrix vesicle plasma cell membrane glycoprotein-1 regulates mineralization by murine osteoblastic MC3T3 cells. J Bone Miner Res. 1999; 14(6):883-892.

26. Cho G, Wu Y, Ackerman JL. Detection of hydroxyl ions in bone mineral by solid-state NMR spectroscopy. Science. 2003;300(5622):1123-1127. 